\title{
Effect of $\mathrm{ZrC}$ Nanopowders on Enhancing the Hydro/Dehydrogenation Kinetics of $\mathrm{MgH}_{2}$ Powders
}

\author{
Mohamed Sherif El-Eskandarany *, Naser Ali ${ }^{(\mathbb{D},}$, Fahad Al-Ajmi ${ }^{\dagger}$ and Mohammad Banyan ${ }^{\dagger}$ (D)
}

Citation: El-Eskandarany, M.S.;

Ali, N.; Al-Ajmi, F.; Banyan, M. Effect of $\mathrm{ZrC}$ Nanopowders on Enhancing the Hydro/Dehydrogenation Kinetics of $\mathrm{MgH}_{2}$ Powders. Molecules 2021, 26, 4962. https://doi.org/10.3390/ molecules26164962

Academic Editor:

Mirjana Dimitrievska

Received: 13 July 2021

Accepted: 4 August 2021

Published: 17 August 2021

Publisher's Note: MDPI stays neutral with regard to jurisdictional claims in published maps and institutional affiliations.

Copyright: (c) 2021 by the authors. Licensee MDPI, Basel, Switzerland. This article is an open access article distributed under the terms and conditions of the Creative Commons Attribution (CC BY) license (https:// creativecommons.org/licenses/by/ $4.0 /)$.
Nanotechnology and Applications Program, Energy and Building Research Center, Kuwait Institute for Scientific Research, Safat 13109, Kuwait; nmali@kisr.edu.kw (N.A.); ftajmi@kisr.edu.kw (F.A.-A.); mbanyan@kisr.edu.kw (M.B.)

* Correspondence: msherif@kisr.edu.kw; Tel.: +965-97308036

+ These authors contributed equally to this work.

\begin{abstract}
Hydrogen has been receiving great attention as an energy carrier for potential green energy applications. Hydrogen storage is one of the most crucial factors controlling the hydrogen economy and its future applications. Amongst the several options of hydrogen storage, light metal hydrides, particularly nanocrystalline magnesium hydride $\left(\mathrm{MgH}_{2}\right)$, possess attractive properties, making them desired hydrogen storage materials. The present study aimed to improve the hydrogen storage properties of $\mathrm{MgH}_{2}$ upon doping with different concentrations of zirconium carbide ( $\mathrm{ZrC}$ ) nanopowders. Both $\mathrm{MgH}_{2}$ and $\mathrm{ZrC}$ were prepared using reactive ball milling and high-energy ball milling techniques, respectively. The as-prepared $\mathrm{MgH}_{2}$ powder was doped with $\mathrm{ZrC}(2,5$, and $7 \mathrm{wt} \%)$ and then high-energy-ball-milled for $25 \mathrm{~h}$. During the ball milling process, $\mathrm{ZrC}$ powders acted as micro-milling media to reduce the $\mathrm{MgH}_{2}$ particle size to a minimal value that could not be obtained without $\mathrm{ZrC}$. The as-milled nanocomposite $\mathrm{MgH}_{2} / \mathrm{ZrC}$ powders consisted of fine particles $(\sim 0.25 \mu \mathrm{m})$ with a nanosized grain structure of less than $7 \mathrm{~nm}$. Besides, the $\mathrm{ZrC}$ agent led to the lowering of the decomposition temperature of $\mathrm{MgH}_{2}$ to $287{ }^{\circ} \mathrm{C}$ and the reduction in its apparent activation energy of desorption to $69 \mathrm{~kJ} / \mathrm{mol}$. Moreover, the hydrogenation/dehydrogenation kinetics of the nanocomposite $\mathrm{MgH}_{2} / \mathrm{ZrC}$ system revealed a significant improvement, as indicated by the low temperature and short time required to achieve successful uptake and release processes. This system possessed a high capability to tackle a long continuous cycle lifetime $(1400 \mathrm{~h})$ at low temperatures $\left(225^{\circ} \mathrm{C}\right)$ without showing serious degradation in its storage capacity.
\end{abstract}

Keywords: hydrogen energy; hydrogen storage; light metal hydrides; reactive ball milling; refractory metal; thermal stability; hydrogenation/dehydrogenation kinetics; cycle lifetime

\section{Introduction}

The global use of fossil fuels has increased drastically as people's standard of living has improved. Climate change, driven by increasing carbon dioxide emissions, will wreak havoc on society [1]. The threat of pollution will be exacerbated by the forced expansion of using low-grade fossil fuels. Improved living standards will raise the demand for chemicals derived from fossil fuels, which will be used to make higher-value end-use commodities such as plastics and pharmaceuticals. Due to the severe rivalry over dwindling supplies, the price of energy and chemicals derived from fossil fuels will increase. Due to environmental and health points of view, fossil fuels emit carbon dioxide and other harmful air pollutants such as $\mathrm{SO}_{2}$ and $\mathrm{NO}_{x}$ when burned [2].

The depletion of fossil fuels is a major motivator for finding clean alternative sources to power energy systems. As a result, using renewable and sustainable energy sources such as solar, wind, and geothermal energy to produce clean and efficient energy systems has become one of the world's hottest research subjects, drawing a large number of academics and researchers [3]. 
Among the different green-energy options, hydrogen, which possesses a high energy density, has been considered the most suitable carbon-free energy carrier that can be used as an alternative to fossil fuel [4]. The convenience, safety, and versatility of hydrogen as an energy carrier are linked to its unique features of being easy to manufacture from a renewable energy system and convert to a desired form of energy [5]. One of the key advantages of hydrogen is that when burned, $\mathrm{CO}_{2}$ is not produced. Fuel cells (FCs) that run on hydrogen offer a wide range of potential uses, ranging from a few watts to gigawatts. Furthermore, compared to an internal combustion engine, hydrogen has the ability to drive a fuel-cell engine more efficiently [6]. The FCs could supply auxiliary power for electrical appliances such as air conditioning and refrigerators in mobile applications [7]. For automobile [8] and vehicle powertrain applications [9], hydrogen-polymer electrolyte membrane (PEM) FCs have become a well-known option [10].

The hydrogen economy and its potential applications are influenced by three variables. Apart from hydrogen generation and transportation, hydrogen storage is seen to be the most important aspect influencing the possible usage of hydrogen in real-world applications. Metal hydrides, notably $\mathrm{MgH}_{2}$, have very appealing features as compared to typical hydrogen storage systems. This system has a higher hydrogen storage density of $6.5 \mathrm{H}$ atoms $/ \mathrm{cm}^{3}$ for $\mathrm{MgH}_{2}$ when compared with pure hydrogen gas $\left(0.99 \mathrm{H}\right.$ atoms $\left./ \mathrm{cm}^{3}\right)$ or liquid hydrogen $\left(4.2 \mathrm{H}\right.$ atoms $\left./ \mathrm{cm}^{3}\right)$. Mg metal has various advantages for hydrogen storage, including low cost, light weight, and high gravimetric $(7.60 \mathrm{wt} \%)$ and volumetric $(110 \mathrm{~g} / \mathrm{L})$ hydrogen storage capacities [11-18]. In spite of the attractive and useful properties of $\mathrm{Mg} / \mathrm{MgH}_{2}$, there are some serious drawbacks that should be solved before using this system for FC-hydrogen storage applications. The tetragonal- $\mathrm{MgH}_{2}$ ( $\beta$-phase) is thermodynamically very stable $\left(\mathrm{H}^{\text {for }}=-75 \mathrm{~kJ} / \mathrm{mol} . \mathrm{H}_{2}\right)$ and decomposes at a high temperature of $350{ }^{\circ} \mathrm{C}$ [19]. Furthermore, it has a high apparent activation energy (above $130 \mathrm{~kJ} / \mathrm{mol}$ ) and very slow hydrogenation/dehydrogenation kinetics under $325^{\circ} \mathrm{C}$ [20].

Within the last three decades, great efforts have been dedicated in order to improve the hydrogen storage behavior of $\mathrm{MgH}_{2}$, using mechanical treatment and catalyzation approaches. Long-term high-energy ball milling [21], cold-rolling [22,23], equal channel angular pressing [24], and high-pressure torsion [25,26] are some techniques used to introduce severe plastic deformation to the $\mathrm{Mg}$ lattice, leading to the destabilization of the $\beta-\mathrm{MgH}_{2}$ phase that tends to transform into a less stable phase $\left(\gamma-\mathrm{MgH}_{2}\right)$ with desired kinetics of hydrogen uptake/release.

Besides the mechanically enhanced approach, a different scenario has been used to improve the behavior of $\mathrm{MgH}_{2}$, using a long list of catalytic agents: pure transition metals such as $\mathrm{Ni}$, Ti, V, and $\mathrm{Nb}$ (see, for example, [27-30]) and their alloys (e.g., TiV [31], CrTi [32], $\mathrm{TiMn}_{2}$ [33], VTiCr [34], and $\mathrm{ZrNi}_{5}$ [17]). Doping $\mathrm{MgH}_{2}$ with different concentrations of such reactive homogeneous and heterogeneous metallic catalysts led to significant improvements in the hydrogenation/dehydrogenation behavior of $\mathrm{MgH}_{2}$. Besides, a new category of metastable metallic alloys, such as big-cube $\mathrm{Zr}_{2} \mathrm{Ni}$ [35] and $\mathrm{Zr}_{70} \mathrm{Ni}_{20}$ $\mathrm{Pd}_{10}$ metallic glass [18] that were successfully used as catalytic agents, led to outstanding improvements in the hydrogen storage properties of $\mathrm{MgH}_{2}$. Additionally, different families of refractory metal compounds, including oxides $\left(\mathrm{Nb}_{2} \mathrm{O}_{5}\right.$ [8], $\mathrm{Cr}_{2} \mathrm{O}_{3}$ [36], $\mathrm{TiO}_{2}$ [37], and $\mathrm{La}_{2} \mathrm{O}_{3}$ [38]), hydrides ( $\mathrm{TiH}_{2}$ [39], $\mathrm{LaH}_{3}$ [40], and $\mathrm{NbH}$ [40]), as well as carbides (e.g., $\mathrm{SiC}$ [41] and $\mathrm{TiC}$ [42]), have been efficiently employed to improve the poor kinetics of $\mathrm{MgH}_{2}$ powders. Within the last decade, some advanced nanocarbon materials, such as single-walled carbon nanotubes [43] and graphene nanofibers [44], have shown remarkable beneficial effects on changing the hydrogen storage properties of $\mathrm{Mg} / \mathrm{MgH}_{2}$. In 2021, a novel catalyzation process was proposed to enhance the thermodynamics and kinetics behaviors of $\mathrm{Mg}$ metal using Ni powders via a cold spray process technique [45].

In the present study, we attempted to improve the kinetics of the uptake/release of $\mathrm{MgH}_{2}$ powders, using a new catalytic agent of $\mathrm{ZrC}$. This compound was selected according to its great hardness value. It can then be expected that upon ball milling with $\mathrm{Mg} / \mathrm{MgH}_{2}$ powders, $\mathrm{ZrC}$ can play a great role as micro-milling media for reducing the particle size of 
the base material, leading to the enhancement of the kinetic characteristics of the hydride phase. Besides, $\mathrm{ZrC}$ with its high thermal stability would not decompose during the hydrogenation process of $\mathrm{Mg}$ metal. Moreover, $\mathrm{ZrC}$ does not react with $\mathrm{Mg}$ and $/$ or $\mathrm{MgH}_{2}$ to form any undesired reactive or intermediate compounds. Thus, it can be safely used as a heterogenous catalytic agent without the drastic decrease in the hydrogen storage capacity of $\mathrm{Mg}$. The present work was undertaken in part to introduce a new nanocomposite system of $\mathrm{MgH}_{2}$-based materials that has an excellent performance of cycle lifetime with fast hydrogenation/dehydrogenation kinetics.

\section{Results and Discussions}

\subsection{Structural Analysis and Morphology}

\subsection{1. $\mathrm{MgH}_{2}$ Nanocrystalline Powders}

An $X$-ray technique was employed to monitor the progress of the gas-solid reaction undertaken between $\mathrm{Mg}$ powders and $\mathrm{H}_{2}$, using the reactive ball milling (RBM) method. The general crystal structural changes in hcp $\mathrm{Mg}$ and the formation of new phases were investigated after the early (1-3 h), intermediate (3-6 h), and final stages of the RBM time. The $X$-ray diffraction (XRD) pattern of the starting feedstock powder, which is displayed in Figure 1a, displayed sharp Bragg-diffraction peaks related to hcp Mg (PDF \# 00-004-0770). After a few minutes (30 min) of RBM, the powders were agglomerated due to the effect of cold welding created by the ball-powder-ball collisions, as displayed in Figure 2a. These agglomerated powders tended to disintegrate into small aggregates $(\sim 20-180 \mu \mathrm{m}$ in diameter) upon the increase in the RBM time to $1 \mathrm{~h}$, as shown in Figure $2 \mathrm{~b}$. The corresponding diffractogram of the disintegrated powders at this stage of RBM time is shown in Figure 1b.

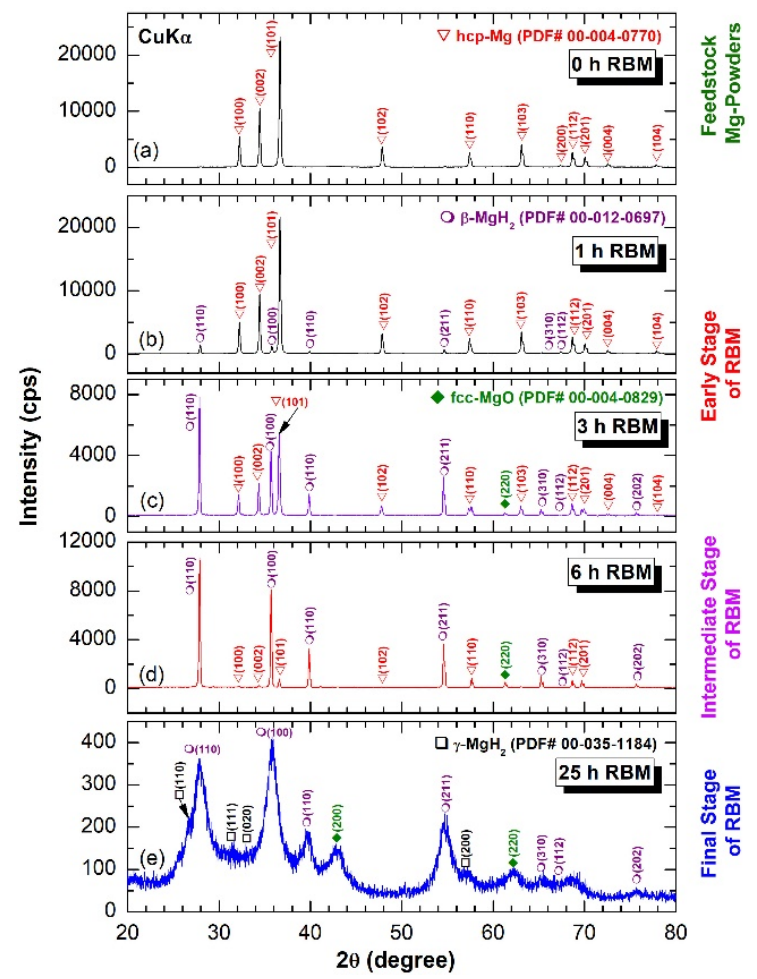

Figure 1. X-ray diffraction (XRD) pattern of as received hcp Mg powder is displayed in (a), where the XRD patterns of the powders obtained after reactive ball milling (RBM) for 1, 3, 6 and $25 \mathrm{~h}$ are presented in (b-e), respectively. 

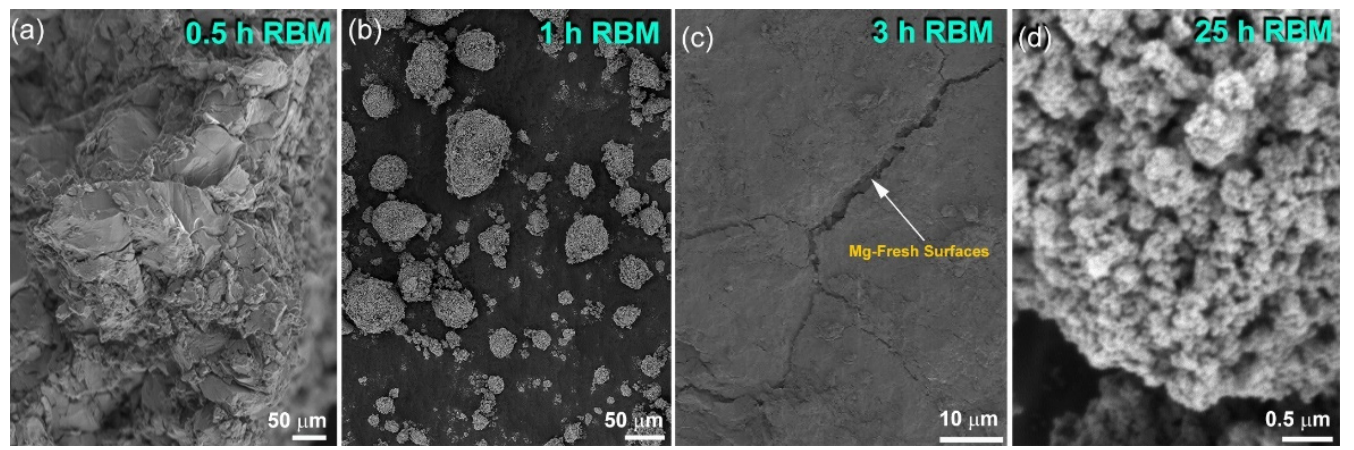

Figure 2. Field-emission scanning electron microscope (FE-SEM) micrographs of Mg powders obtained after RBM under pressurized hydrogen for (a) 0.5 , (b) 1 , (c) 3 and (d) $25 \mathrm{~h}$.

Besides the Bragg peaks of unreacted hcp peaks, low-intensity diffracted lines were detected, suggesting the formation of the reacted $\beta-\mathrm{MgH}_{2}$ phase (PDF \# 00-012-0697), as presented in Figure $1 \mathrm{~b}$. At the intermediate stage of RBM (3-6 h), the large Mg aggregates were disintegrated along their grain boundaries to form smaller grains with new active surfaces, as displayed in Figure 2c. Initiation of these new surfaces promoted a forward gas-solid reaction and the formation of a reactive $\mathrm{MgH}_{2}$ phase. This is implied by the formation of pronounced high-intensity Bragg lines, which corresponded to the $\beta-\mathrm{MgH}_{2}$ phase (Figure 1c). The formation of larger volume fractions of fresh surface $\mathrm{Mg}$ powders upon increasing the RBM time $(6 \mathrm{~h})$ enhanced the reaction between the diffusion couples $\left(\mathrm{Mg}\right.$ and $\mathrm{H}_{2}$ ), leading to increases in the volume fraction of the reacted phase against pure $\mathrm{Mg}$ metal. Accordingly, the Bragg peaks related to hcp Mg were hardly detected in the diffractogram related to the powders obtained after $6 \mathrm{~h}$ of RBM (Figure 1d).

Severe lattice imperfections were continuously developed in the $\mathrm{MgH}_{2}$ lattice upon increasing the RBM time to $18 \mathrm{~h}$, as indexed by the staking faults appearing in $\beta-\mathrm{MgH}_{2}$ (002), as shown in Figure 3a,b. The generation of these lattice imperfections led to further disintegration of the $\mathrm{MgH}_{2}$ powders and the formation of nanocluster powder particles after $25 \mathrm{~h}$ (Figure 2d). The XRD pattern of this end-product revealed significant broadening, obtained as a result of the grain refinement and lattice strain, as displayed in Figure 1e. The existence of metastable $\gamma-\mathrm{MgH}_{2}$ (PDF\# 00-035-1184) was produced due to distortion of the most stable phase of $\beta-\mathrm{MgH}_{2}$ (Figure 1e).

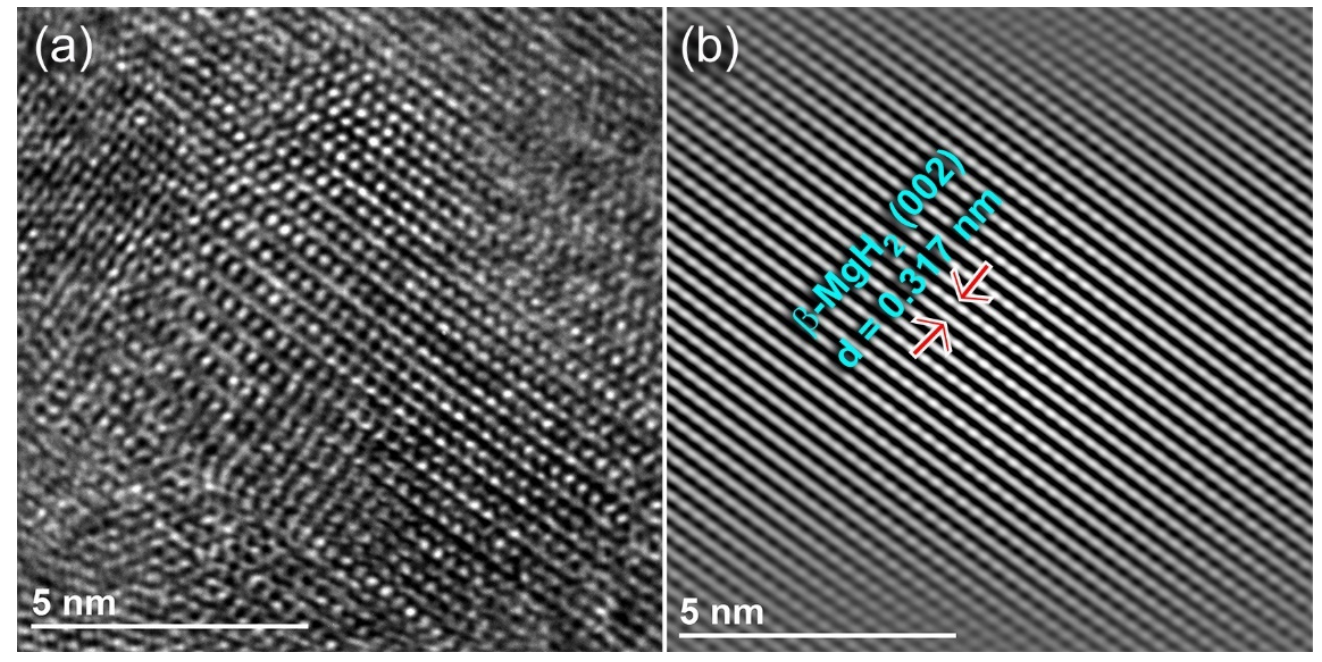

Figure 3. (a) Field emission high-resolution transmission electron microscope (FE-HRTEM) image of $\mathrm{MgH}_{2}$ powders obtained after $18 \mathrm{~h}$ of RBM. The filtered-atomic-scale TEM image of the fringe image in (a) is present in (b). 


\subsubsection{ZrC Catalytic Agent Nanopowders}

For the present work, equiatomic nanocrystalline fcc-ZrC powders were synthesized from elemental $\mathrm{Zr}$ and graphite powders, using a high-energy ball mill (HEBM). Figure $4 \mathrm{a}, \mathrm{b}$ display the XRD patterns for the starting feedstock powders of hcp Zr (PDF File\# 00-005-065) and hcp-C (PDF File\# 00-056-0159), respectively. A new phase was detected after $25 \mathrm{~h}$ of HEBM, as indexed in the XRD pattern shown in Figure 4c. Analysis of the diffracted lines that matched well with PDF File\# 00-19-1487 indicated the formation of a single phase of fcc-ZrC. The HEBM ZrC powders had a cluster-like morphology composed of spherical nanoparticles with a diameter of less than $50 \mathrm{~nm}$ (Figure 4d). The field emission high-resolution transmission electron microscope (FE-HRTEM) image indicated the formation of uniform nanospheres in the range between 2 and $7 \mathrm{~nm}$ in diameter, as shown in Figure 4e. Moreover, the corresponding nanobeam diffraction pattern (NBDP), implied the formation of fcc $\mathrm{ZrC}$, characterized by (111), (200), (220) and (311), as displayed in Figure $4 \mathrm{f}$. The absence of sharp spots from the Debye-Scherrer rings implied the existence of nanocrystalline $\mathrm{ZrC}$ powders.
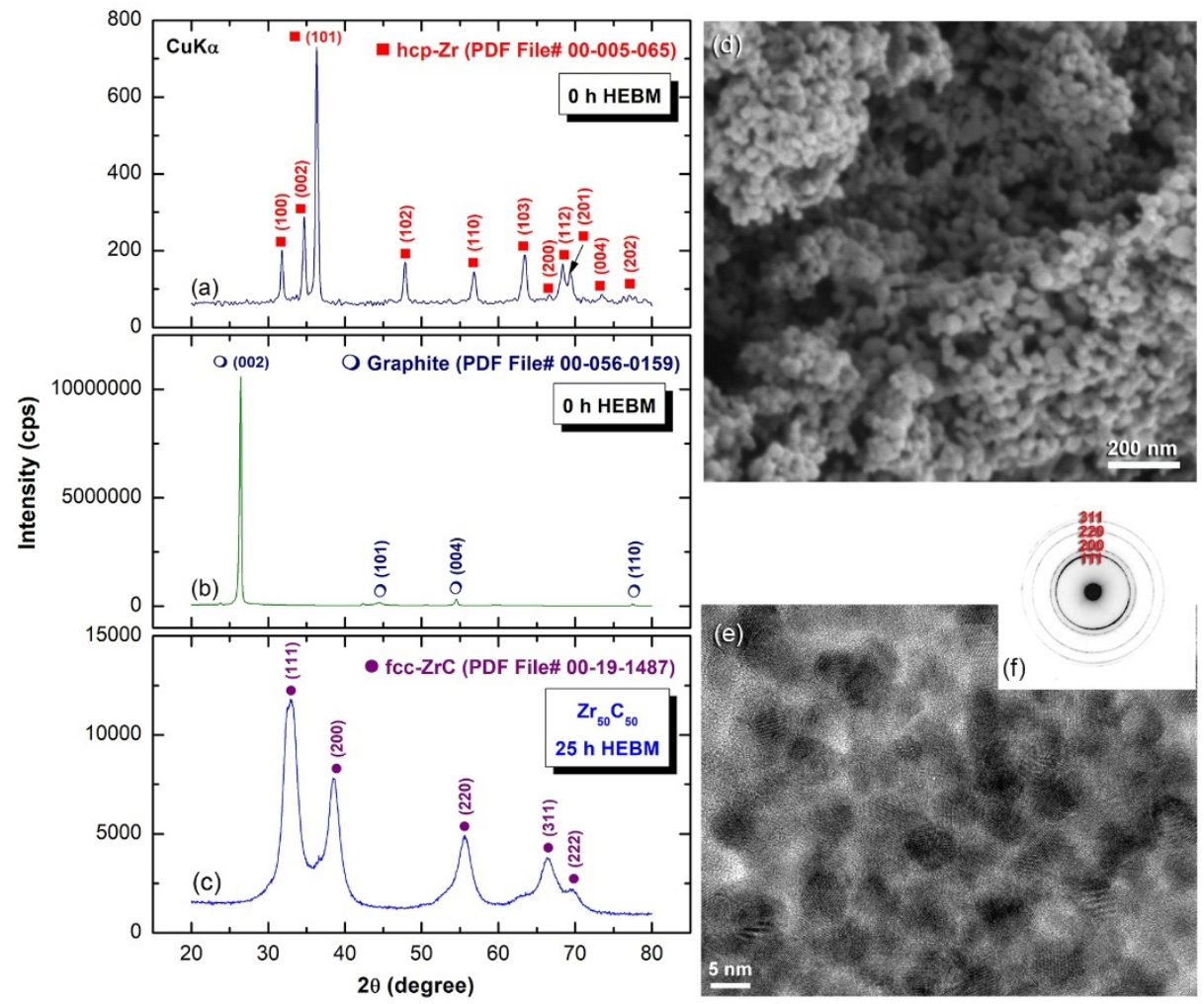

Figure 4. XRD patterns of (a) as-received hcp-Zr and (b) graphite powders. The XRD pattern of equiatomic fcc-ZrC nanopowders obtained after $25 \mathrm{~h}$ of high-energy ball milling (HEBM) is displayed in (c). The morphological characteristics of as-prepared fcc- $\mathrm{ZrC}$ powders are indexed in (d) and (e) by FE-SEM and FE-HRTEM, respectively. The nanobeam diffraction pattern (NBDP) taken from the middle zone of $(\mathbf{e})$ is presented in $(\mathbf{f})$.

\subsubsection{Nanocomposite $\mathrm{MgH}_{2} / \mathrm{x}-\mathrm{ZrC}(\mathrm{x} ; 2,5$ and 7 wt.\%) Powders}

The $\mathrm{ZrC}$ nanoparticles obtained after $25 \mathrm{~h}$ of milling were used to improve the hydrogen storage characteristics of $\mathrm{MgH}_{2}$ powders upon mechanically induced mixing for $50 \mathrm{~h}$ with different mass fractions $(2,5$, and $7 \mathrm{wt} . \%)$, using HEBM. The XRD pattern of nanocomposite $\mathrm{MgH}_{2} / 5 \mathrm{wt} . \% \mathrm{ZrC}$ powders obtained after $50 \mathrm{~h}$ of HEBM is displayed in Figure 5a. The diffractogram possessed broad Bragg peaks of the base $\mathrm{MgH}_{2}$ powders and the modifier agent of $\mathrm{ZrC}$, as presented in Figure 5a. Both phases kept their existence after milling for $50 \mathrm{~h}$ with no evidence for the formation of any reacted phase. 

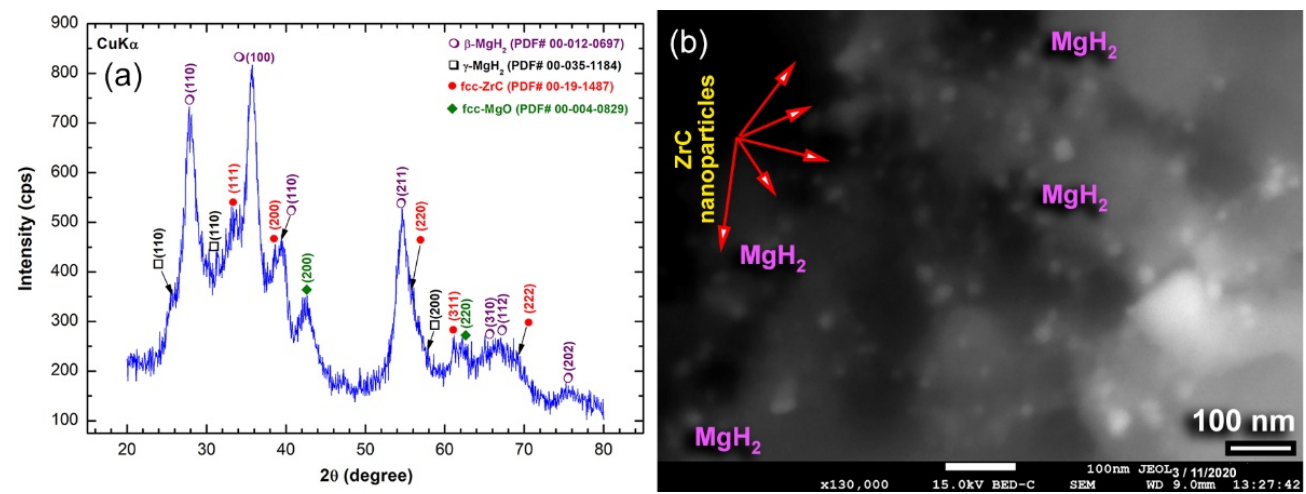

Figure 5. (a) XRD pattern and (b) back-scattering electron FE-SEM micrograph of mechanically mixed $\mathrm{MgH}_{2} / 5 \mathrm{wt}$.\% $\mathrm{ZrC}$ nanocomposite powders obtained after $50 \mathrm{~h}$ of HEBM. The nanodispersoid $\mathrm{ZrC}$, which are indexed by the red arrow labels in (b), were embedded into the $\mathrm{MgH}_{2}$ powder matrix.

The atomic-resolution TEM image of the nanocomposite powders obtained after $50 \mathrm{~h}$ of milling is presented in Figure 6. The figure shows two individual $\mathrm{MgH}_{2}$ particles, indexed by $\beta-\mathrm{MgH}_{2}$ (110) and (101). Meanwhile, two $\mathrm{ZrC}$ nanoparticles, characterized by fcc $-\mathrm{ZrC}$ (111) and (200), were adhered to the $\mathrm{MgH}_{2}$ particles, as displayed in Figure 6. Examining the local structure of the interfaces between these two different materials beyond the atomic level suggested the absence of any reacted phase(s). This implies that $\mathrm{ZrC}$ was natural during milling with $\mathrm{MgH}_{2}$ powders and played the role of a heterogeneous catalyst. It is worth mentioning that the positions of the Bragg peak for $\mathrm{MgH}_{2}$ shifted to the lowangle side, suggesting the expansion of the lattice parameter without altering the crystal.

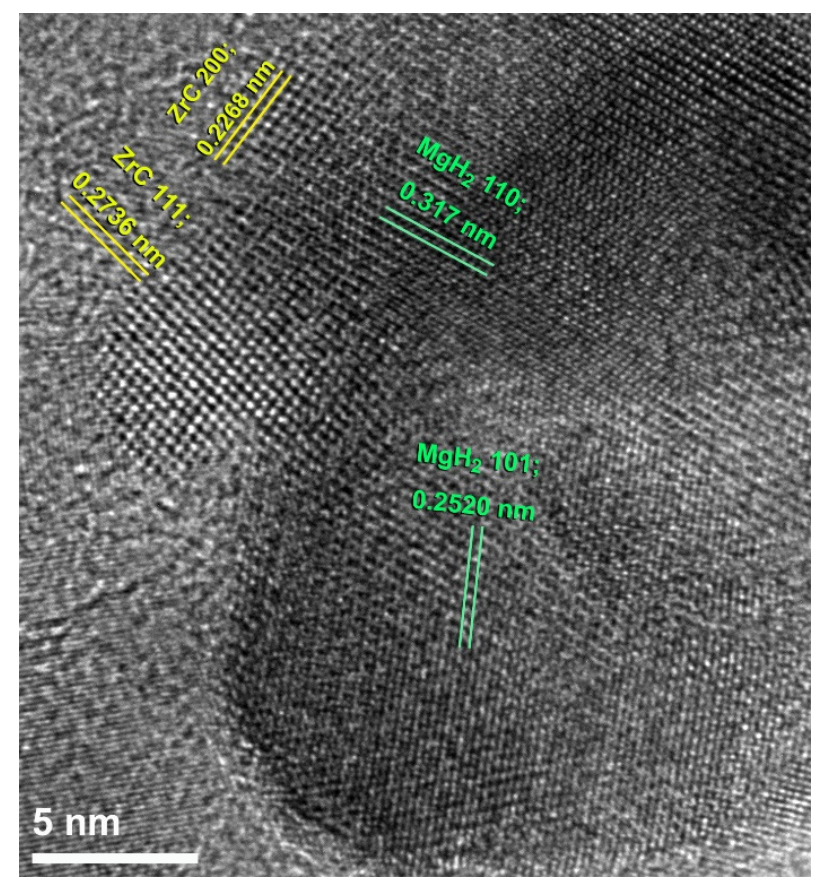

Figure 6. FE-HRTEM with atomic resolution of nanocomposite $\mathrm{MgH}_{2} / 5$ wt. $\% \mathrm{ZrC}$ powders obtained after $50 \mathrm{~h}$ of HEBM.

Besides, the Bragg lines of $\mathrm{MgH}_{2}$ had become broader, when compared with the original diffractogram of as-prepared $\mathrm{MgH}_{2}$ powders (Figure 1e). This may suggest the synergetic effect of further milling with $\mathrm{ZrC}$ hard powders (Figure 5a). The back scattering electron micrograph, using a $15 \mathrm{kV}$ FE-SEM with a BSE detector (BED) for the nanocomposite $\mathrm{MgH}_{2} / 5 \mathrm{wt} . \% \mathrm{ZrC}$, obtained after $25 \mathrm{~h}$ of HEBM, is shown in Figure $5 \mathrm{~b}$. 
The powders were composed of $\mathrm{MgH}_{2}$ matrix, where spherical $\mathrm{ZrC}$ nanoparticles $(<10 \mathrm{~nm})$ were embedded uniformly into the matrix.

The distribution of $\mathrm{ZrC}$ nanoparticles in $\mathrm{MgH}_{2}$ powders after processing for $25 \mathrm{~h}$ of HEBM was investigated by intensive EDS analysis, using FE-SEM. Figure 7a displays a FE-SEM micrograph of nanocomposite $\mathrm{MgH}_{2} / 5 \mathrm{wt} . \% \mathrm{ZrC}$ powder obtained after $25 \mathrm{~h}$ of milling. The indexed rectangular zone $(5 \mu \mathrm{m} \times 4 \mu \mathrm{m})$, shown in the middle part of the micrograph, refers to the selected area chosen for EDS analysis. The area was classified into subrectangular zones $(0.5 \mu \mathrm{m} \times 0.4 \mu \mathrm{m})$, where the analysis was conducted in the middle of each subzone (Figure 7a). In general, the powder obtained after this stage of HEBM possessed a narrow distribution particle size range (100-300 nm) with a spherical-like morphology, as shown in Figure 7a. We should emphasize that refractory $\mathrm{ZrC}$ nanopowders played the role of micro-milling media and led to drastic grain refining of the $\mathrm{MgH}_{2}$ powders.

(a)
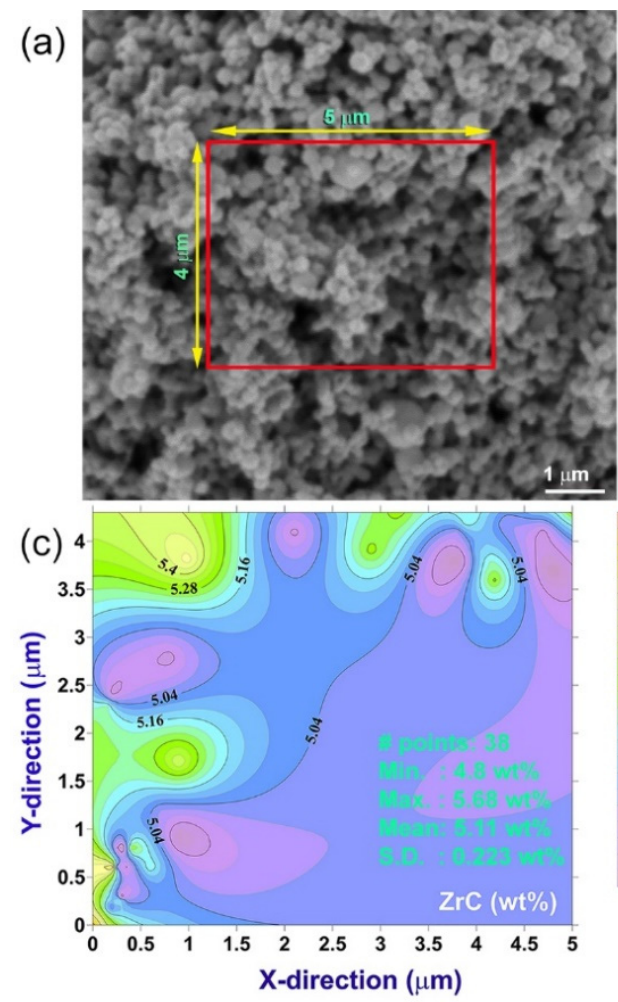
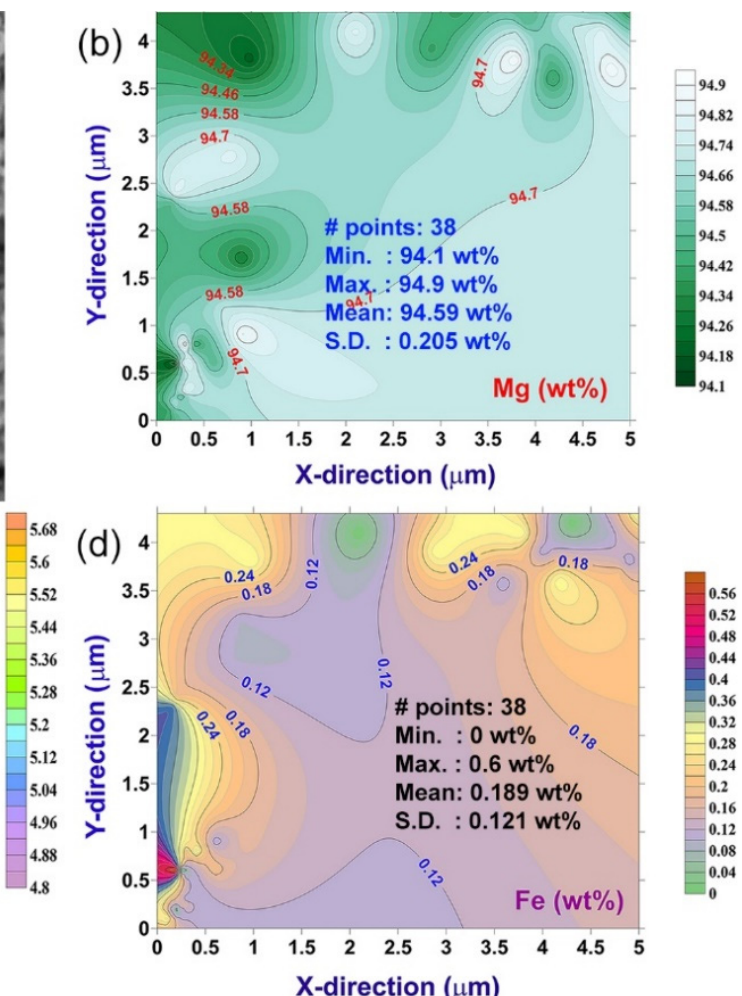

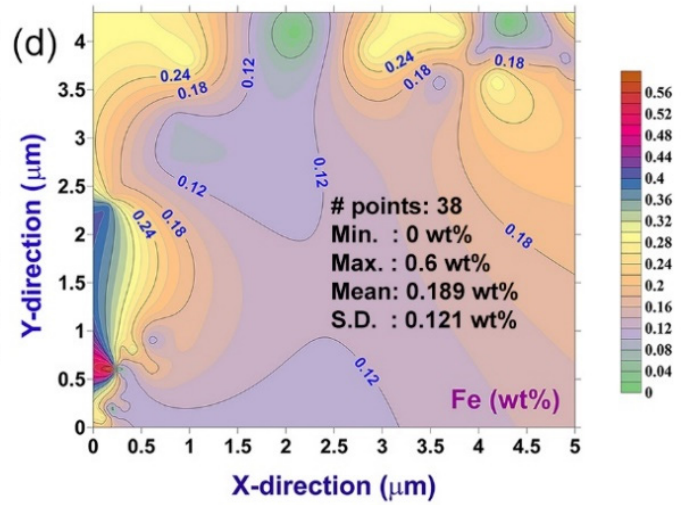

Figure 7. (a) FE-SEM micrograph of mechanically mixed $\mathrm{MgH}_{2} / 5 \mathrm{wt} \% \mathrm{ZrC}$ nanocomposite powders obtained after $50 \mathrm{~h}$ of HEBM. The indexed rectangular zone $(4 \mathrm{~cm} \times 5 \mathrm{~cm})$ shown in (a) refers to the analytical area, in which intensive EDS analysis was conducted. The corresponding isochemical contour maps of $\mathrm{Mg}, \mathrm{ZrC}$, and Fe contamination are displayed in $(\mathbf{b}-\mathbf{d})$, respectively.

In addition, further ball milling time $(50 \mathrm{~h})$ promoted a homogeneous distribution of nanograined $\mathrm{ZrC}$ powders into the metal hydride matrix. The compositional analysis obtained from EDS measurements was employed to design isochemical contour maps for $\mathrm{Mg}$ (Figure 7b), ZrC (Figure 7c), and Fe (Figure 7d). The Fe was introduced to the nanocomposite powders due to using tool-steel milling tools. The contour intervals were selected to cover all concentrations of $\mathrm{Mg}$ (94.34-94.7 wt.\%), ZrC (5.04-5.4 wt.\%), and Fe (0.12-0.24 wt.\%), as shown in Figure $7 \mathrm{~b}-\mathrm{d}$, respectively.

No obvious degradation in $\mathrm{ZrC}$ concentration or drastic compositional gradient could be detected, suggesting a uniform distribution of $\mathrm{ZrC}$ nanoparticles into the $\mathrm{MgH}_{2}$ matrix. The average concentrations of $\mathrm{Mg}$ and $\mathrm{ZrC}$ were $94.9 \mathrm{wt} . \%$ (Figure $7 \mathrm{~b}$ ) and $5.11 \mathrm{wt} . \%$ (Figure 7c), respectively. The powders, however, were contaminated with about 0.19 wt.\% of Fe (Figure 7d). 


\subsection{Thermal Stability}

Atmospheric helium-pressure DSC was employed to investigate the thermal stability, indexed by decomposition temperature $\left(T_{p}\right)$ and activation energy $\left(E_{a}\right)$, for synthesized nanocrystalline $\mathrm{MgH}_{2}$ before and after doping with $\mathrm{ZrC}$ nanoparticles. The DSC thermogram of $\mathrm{MgH}_{2}$ nanopowders, obtained after $50 \mathrm{~h}$ of $\mathrm{RBM}$, are displayed in Figure 8a with different heating rates $(\mathrm{k})$ of $5,10,20,30$, and $40^{\circ} \mathrm{C} / \mathrm{min}$. All the scans revealed single endothermic events related to the decomposition of the $\mathrm{MgH}_{2}$ phase. This is implied by the XRD pattern of the sample heated up to $500{ }^{\circ} \mathrm{C}$, which revealed sharp Bragg peaks related to pure $\mathrm{Mg}$ and fcc $\mathrm{ZrC}$ overlapped with an undecomposed minor volume fraction of $\mathrm{MgH}_{2}$, as displayed in Figure 9. While the peak height increased proportionally with the increase in $\mathrm{k}, \mathrm{T}_{\mathrm{p}}$ significantly shifted to the higher-temperature side upon the increase in the heating rates from 5 to $40^{\circ} \mathrm{C} / \mathrm{min}$, as shown in Figure 8a. The as-synthesized $\mathrm{MgH}_{2}$ nanopowders revealed a high decomposition temperature, exemplified by the $\mathrm{T}_{\mathrm{p}}$ measured at $10^{\circ} \mathrm{C} / \mathrm{min}\left(360^{\circ} \mathrm{C}\right)$, as shown in Figure 8 a.
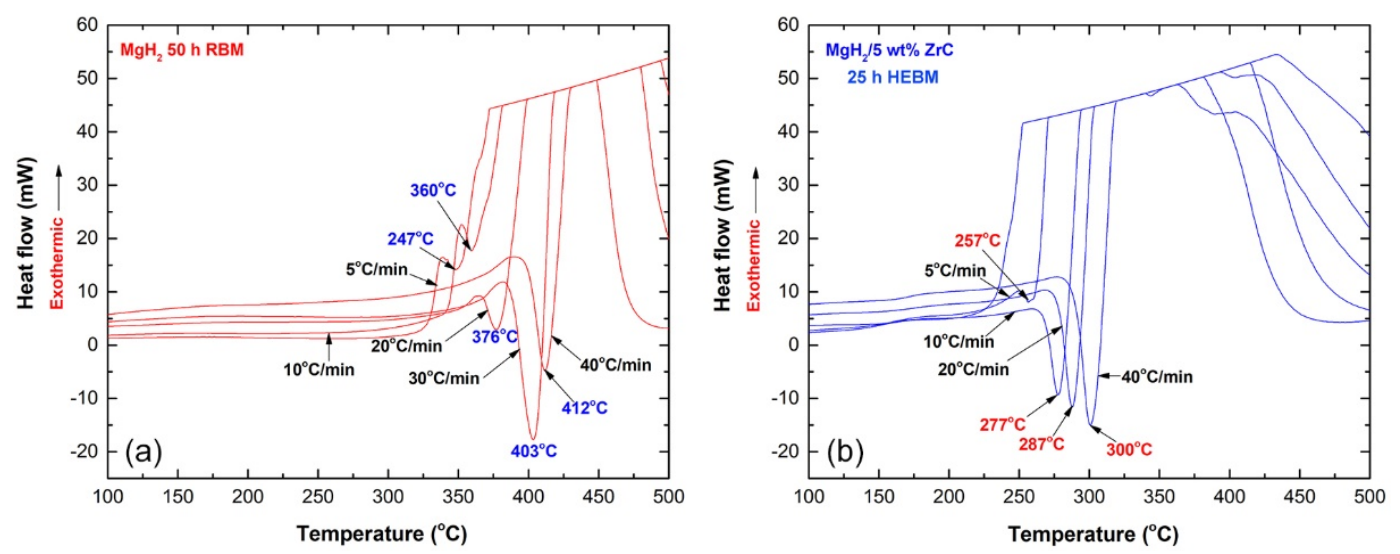

Figure 8. DSC thermograms conducted at heating rates of $5,10,20,30$, and $40{ }^{\circ} \mathrm{C} / \mathrm{min}$ for (a) $\mathrm{MgH}_{2}$ powders, obtained after $50 \mathrm{~h}$ of $\mathrm{RBM}$, and (b) mechanically mixed $\mathrm{MgH}_{2} / 5 \mathrm{wt} \% \mathrm{ZrC}$ nanocomposite powders obtained after $25 \mathrm{~h}$ of $\mathrm{HEBM}$.

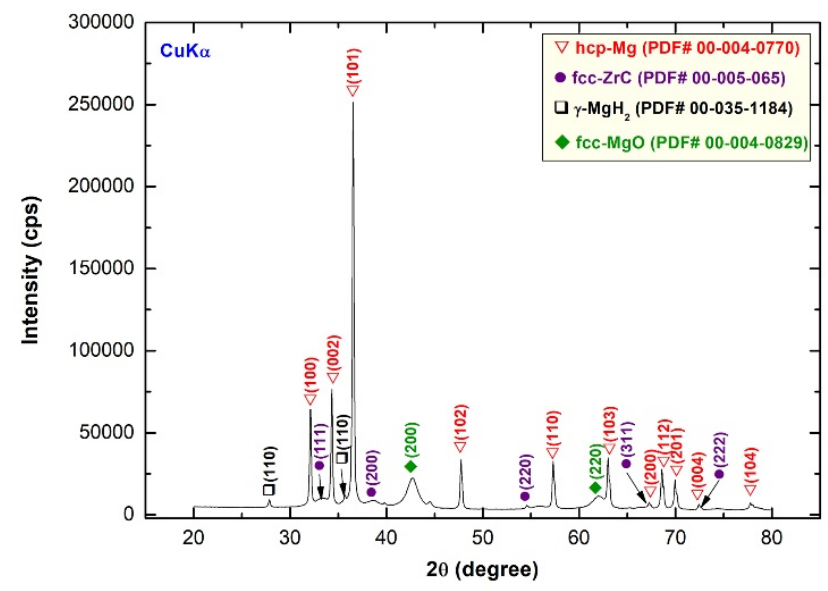

Figure 9. XRD pattern of nanocomposite $\mathrm{MgH}_{2} / 5 \mathrm{wt} . \% \mathrm{ZrC}$ milled for $25 \mathrm{~h}$ of $\mathrm{HEBM}$ and then heated up to $500{ }^{\circ} \mathrm{C}$ in a DSC under the flow of He gas.

The improved dehydrogenation kinetics, measured under a helium gas atmosphere, was evaluated by calculating the $\mathrm{E}_{\mathrm{a}}$ of the decomposition reaction for both pure $\mathrm{MgH}_{2}$ and corresponding $\mathrm{MgH}_{2} / 5 \mathrm{wt} . \% \mathrm{ZrC}$ samples. In the present work, the activation energy for dehydrogenation was investigated according to the Arrhenius Equation (1):

$$
\mathrm{E}_{\mathrm{a}}=-\mathrm{RT}_{\mathrm{p}} \ln \left(\mathrm{k} / \mathrm{k}_{0}\right)
$$


where $\mathrm{k}$ is a temperature-dependent reaction rate constant, $\mathrm{R}$ is the gas constant, and $\mathrm{Tp}$ is the absolute temperature. The value $\mathrm{E}_{\mathrm{a}}$ of the reaction was determined by measuring the decomposition of $\mathrm{T}_{\mathrm{p}}$ corresponding to the different heating rates $(\mathrm{k})$ and then plotting $\ln (\mathrm{k})$ versus $1 / T_{p}$, where the $E_{a}$ of synthesized $\mathrm{MgH}_{2}$ nanopowders was $123 \mathrm{~kJ} / \mathrm{mol}$, and the $E_{a}$ obtained for nanocomposite $\mathrm{MgH}_{2} / 5 \mathrm{wt} . \% \mathrm{ZrC}$ was $69 \mathrm{~kJ} / \mathrm{mol}$. This indicates a significant destabilization of the $\mathrm{MgH}_{2}$ upon doping with $5 \mathrm{wt} . \% \mathrm{ZrC}$.

\subsection{Pressure-Composition-Temperature}

Pressure-composition-temperature (PCT), also known as pressure-composition isotherms (PCI), is the most basic measurement, used to investigate the thermodynamic properties of a hydrogen storage system. The PCT correlations of nanocomposite $\mathrm{MgH}_{2} / 5 \mathrm{wt} . \% \mathrm{ZrC}$ powders, obtained after $25 \mathrm{~h}$ of HEBM, were volumetrically investigated by Sievert's approach at different temperatures of 225, 250, 275, 300 and $325^{\circ} \mathrm{C}$, as displayed in Figure 10a. The PCT measurements were started by introducing $\mathrm{H}_{2}$ to the system at the desired temperature, and then the system was closed while the sample and gas reacted under isochoric conditions. All PCT experiments were achieved, using the run-of-RBM (raw-nanocomposite powders), before conducting powder activation. This was necessary in order to realize the original shape of the PCT curve, and its slope. In all applied temperatures, single reversible hydrogenation/dehydrogenation cycles were characterized, with the absence of wide pressure gaps $(\Delta \mathrm{P})$ between the hydrogenation $\left(\mathrm{P}^{\mathrm{abs}}\right)$ and dehydrogenation $\left(\mathrm{P}^{\mathrm{des}}\right)$ plateaus, as shown in Figure 10b. Accordingly, the near values of $\Delta \mathrm{P}\left(\Delta \mathrm{P}=\mathrm{P}^{\text {abs }}-\mathrm{P}^{\text {des }}\right)$ indicate the absence of the hysteresis phenomenon for this hydrogen storage nanocomposite system, as can be realized in Figure 10a,b.

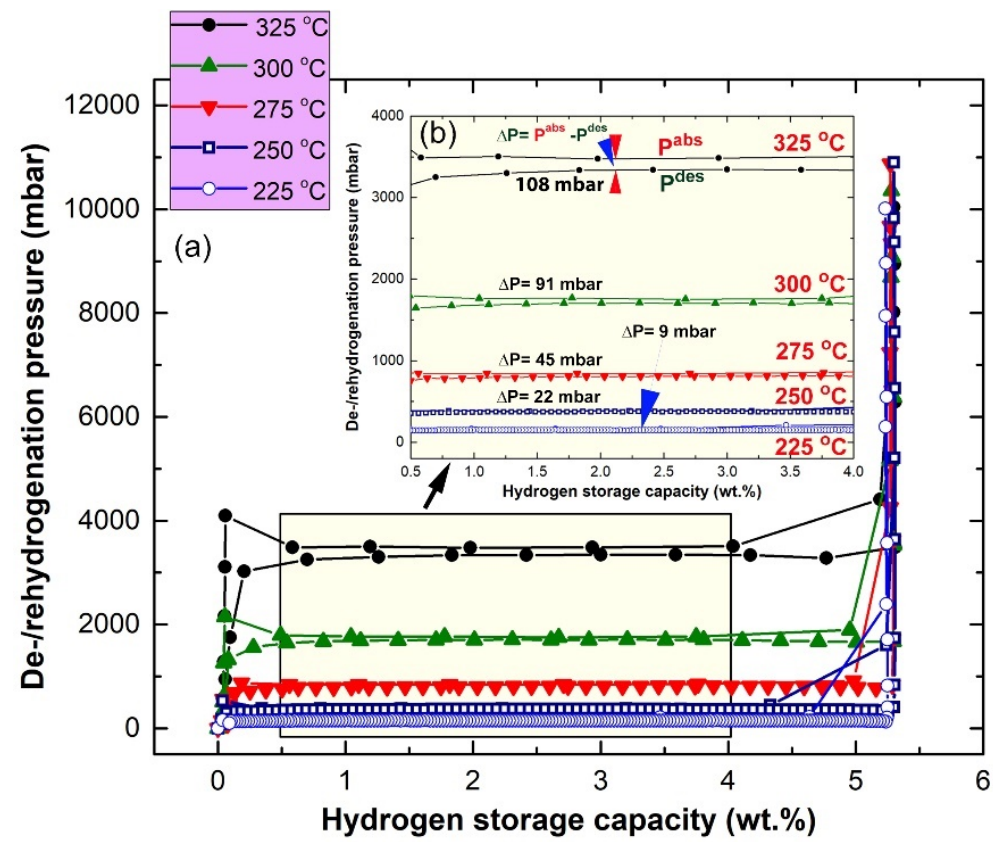

Figure 10. Pressure-composition-temperature (PCT) curves conducted at 225, 250, 275, 300 and $325{ }^{\circ} \mathrm{C}$ for nanocomposite $\mathrm{MgH}_{2} / 5 \mathrm{wt}$ \% $\mathrm{ZrC}$ obtained $25 \mathrm{~h}$ of HEBM. (a) Sievert's approach at different temperatures $(\mathbf{b})$ wide pressure gaps $(\Delta \mathrm{P})$ between the hydrogenation $\left(\mathrm{P}^{\mathrm{abs}}\right)$ and dehydrogenation $\left(\mathrm{P}^{\mathrm{des}}\right)$ plateaus.

Moreover, the presence of single clear hydrogenation/dehydrogenation plateaus can be seen in the range between 0.5 and $4 \mathrm{wt} . \% \mathrm{H}_{2}$ at all temperature ranges (Figure 10a). Smooth plateaus of hydrogen uptake/release were characterized in the whole hydrogen concentrations range $\left(0.25-5.25 \mathrm{wt} . \% \mathrm{H}_{2}\right)$ for all applied temperatures, as presented in 
Figure 10b. The hydrogen equilibrium pressure measurements were used in the present study to investigate the heat of hydrogen absorption, using the van't Hoff Equation (2):

$$
\ln \left(\frac{P_{e q}}{P_{o}}\right)=-\left(\frac{\Delta H}{R T}+\frac{\Delta S}{R}\right)
$$

where $P_{e q}$ is the hydrogen pressure under equilibrium at a given specific temperature, $T ; P_{o}$ is a reference pressure of $1 \mathrm{bar} ; R$ is the gas constant $(0.0083145 \mathrm{~J} / \mathrm{K} . \mathrm{mol}) ; \Delta H$ is the molar enthalpy of metal hydride formation $\left(\mathrm{MgH}_{2}\right)$; and $\Delta S$ is the entropy of absorption. The $\Delta H$ of hydrogenation can be directly calculated from plotting the natural $\log$ of each $P_{e q}$ point versus the corresponding $1 / T$, as shown in Figure 11a.

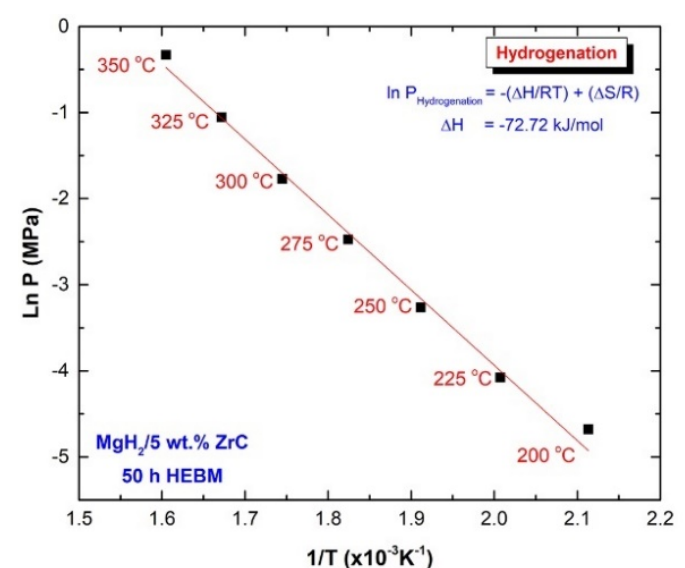

(a)

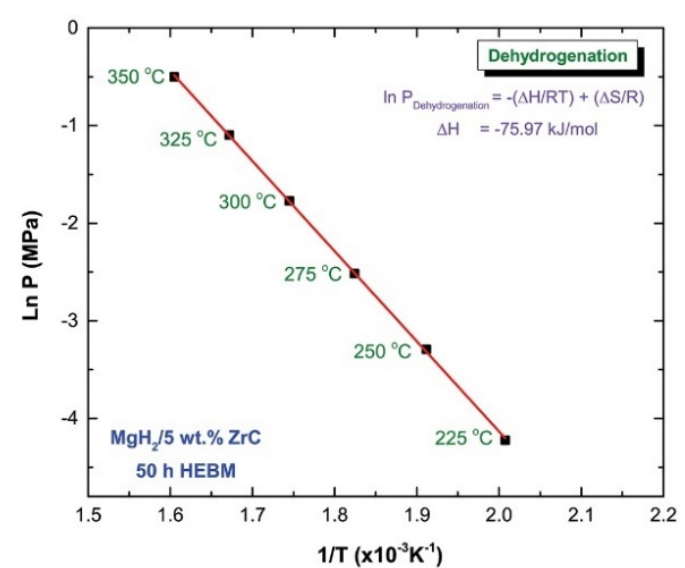

(b)

Figure 11. Van't Hoff plot of the plateaus shown respectively in Figure 10 a for hydrogenation (a) and 10b dehydrogenation (b) of nanocomposite $\mathrm{MgH}_{2} / 5$ wt. $\% \mathrm{ZrC}$ obtained after $25 \mathrm{~h}$ of HEBM.

In the present work, the calculated $\Delta H$ and $\Delta S$ for $\mathrm{MgH}_{2}$ doped with $5 \mathrm{wt} . \% \mathrm{ZrC}$ were $-72.74 \mathrm{~kJ} / \mathrm{mol}$ and $112.79 \mathrm{~J} / \mathrm{mol} \mathrm{H}_{2} / \mathrm{K}$, respectively. On the other hand, the strength of $\mathrm{Mg}-\mathrm{H}$ bonds, which is indicated by the enthalpy of decomposition, can be calculated via the van't Hoff approach, using the equilibrium dehydrogenation pressure in the PCT measurements. The $\Delta H$ of decomposition and the corresponding $\Delta S$ of the nanocomposite $\mathrm{MgH}_{2} / 5$ wt. $\% \mathrm{ZrC}$ were calculated for the slope of the line displayed in Figure 11b, and they were found to be $75.97 \mathrm{~kJ} / \mathrm{mol}$ and $119.15 \mathrm{~J} / \mathrm{mol} \mathrm{H}_{2} / \mathrm{K}$, respectively.

\subsection{Hydrogenation/Dehydrogenation Kinetics}

\subsection{1. $\mathrm{MgH}_{2}$ Nanocrystalline Powders}

Figure 12a,b display the synergetic effect of RBM time and applied temperature on the hydrogenation and dehydrogenation kinetics of $\mathrm{RBM} \mathrm{MgH}_{2}$ powders obtained after $50 \mathrm{~h}$ of milling, respectively. As expected, the synthesized pure $\mathrm{MgH}_{2}$ powders exhibited poor hydrogenation/dehydrogenation kinetics, particularly at applied temperatures of less than $325^{\circ} \mathrm{C}$, as shown in Figure 12. For example, the times required to uptake and discharge $\sim 6.5$ wt. $\% \mathrm{H}_{2}$ at $325{ }^{\circ} \mathrm{C}$ were $2500 \mathrm{~s}$ and $7800 \mathrm{~s}$, as presented in Figure 12a,b, respectively. The absorption and desorption kinetics dropped significantly upon decreasing the temperature to $275^{\circ} \mathrm{C}$. This is indicated by the time necessary to absorb $(\sim 2500 \mathrm{~s})$ and desorb ( 40,000 s) 6.28 wt.\% $\mathrm{H}_{2}$, as presented in Figure 12a,b, respectively.

\subsubsection{Nanocomposite $\mathrm{MgH}_{2} / \mathrm{x}-\mathrm{ZrC}(\mathrm{x} ; 2,5$, and 7 wt.\%) Powders}

Figure 13 summarizes the hydrogenation/dehydrogenation kinetics obtained at selected temperatures upon mechanical mixing of nanocrystalline $\mathrm{MgH}_{2}$ powders with different concentrations (2, 5, and $7 \mathrm{wt}$ \% $)$ of $\mathrm{ZrC}$ nanopowder particles. The $\mathrm{MgH}_{2} / 5 \mathrm{wt} . \%$ $\mathrm{ZrC}$ system possessed excellent hydrogenation kinetics, suggested by its capability of 
absorbing $1.9,0.7,0.6$, and $0.3 \mathrm{wt} . \% \mathrm{H}_{2}$ at ambient temperature under pressures of 40,30 , 20, and 1 bar (Figure 13a).
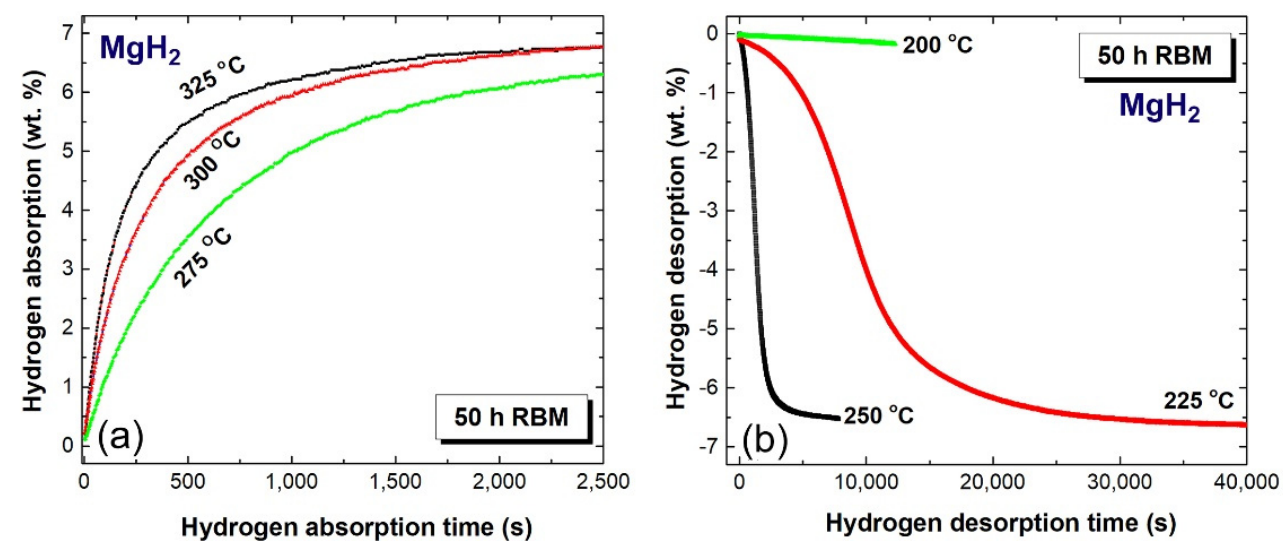

Figure 12. Kinetics measured at 275,300 and $350{ }^{\circ} \mathrm{C}$ of (a) hydrogenation and (b) dehydrogenation of $\mathrm{MgH}_{2}$ powders obtained after $50 \mathrm{~h}$ of RBM.
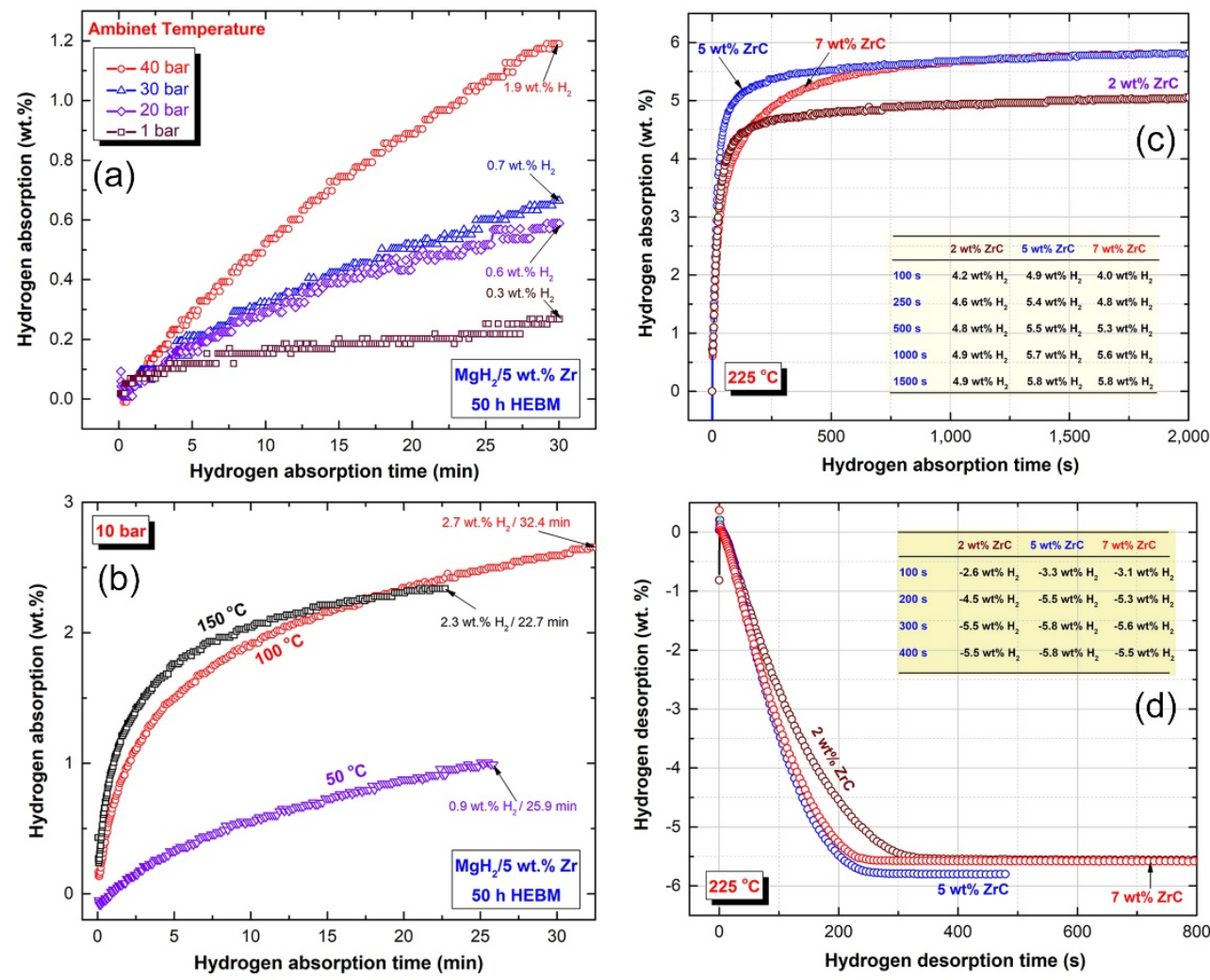

Figure 13. Hydrogenation kinetics of $\mathrm{MgH}_{2} / 5 \mathrm{wt} . \% \mathrm{ZrC}$ system, measured at (a) ambient temperature under hydrogen pressures of $1,20,30$, and $40 \mathrm{bar}$, and (b) 50,100, and $150{ }^{\circ} \mathrm{C}$ under a hydrogen pressure of $10 \mathrm{bar}$. The hydrogenation and dehydrogenation kinetics measured at $225^{\circ} \mathrm{C}$ under 10 and $0.04 \mathrm{H}_{2}$ bar of $\mathrm{MgH}_{2} / \mathrm{x}-\mathrm{wt}$. $\% \mathrm{ZrC}(\mathrm{x} ; 2,5,7)$ are presented in $(c, d)$, respectively.

Under an applied pressure of $10 \mathrm{bar}$, this system showed a good ability of absorbing 2.7 and 2.3 wt. $\% \mathrm{H}_{2}$ within 32.4 and $22.7 \mathrm{~min}$ at low temperatures of 100 and $150{ }^{\circ} \mathrm{C}$, respectively, as displayed in Figure 13b. It is worth mentioning that the system was able to absorb $0.9 \mathrm{wt} . \% \mathrm{H}_{2}$ within $25.9 \mathrm{~min}$ at $50{ }^{\circ} \mathrm{C}$ under $10 \mathrm{bar}$, as shown in Figure 13b. Figure 13d displays the effect of $\mathrm{ZrC}$ nanopowder on improving the dehydrogenation kinetics of $\mathrm{MgH}_{2}$ powder. As shown in the figure, $\mathrm{MgH}_{2}$ doped with 2, 5 and $7 \mathrm{wt} . \% \mathrm{ZrC}$ 
possessed excellent releasing kinetics, indicated by the relatively short time (200 s) needed to desorb about $-4.5,-5.5$, and $5.3 \mathrm{wt} . \%$, respectively. After $400 \mathrm{~s}$, the three systems approached saturated values in the range between -5.5 and $-5.8 \mathrm{wt} \% \mathrm{H}_{2}$ (Figure $13 \mathrm{~d}$ ).

\subsection{Cycle Lifetime}

To obtain more information of the capability of the nanocomposite $\mathrm{MgH}_{2} / 5 \mathrm{wt} \%$ $\mathrm{ZrC}$ system to perform a large number of uptake/release cycles without degradation, the powders were first activated at a higher temperature of $275{ }^{\circ} \mathrm{C}$ under hydrogenation/dehydrogenation hydrogen pressures of 35 and 0.2 bar, respectively. This activation step was required to improve the hydrogen storage capacity, which reached $6.9 \mathrm{wt} . \%$, as shown in Figure 14a. During the thermal treatment (surface cleaning) under such high pressure and temperature, the bonding between $\mathrm{Mg}$ and $\mathrm{O}_{2}$ tended to break down. Accordingly, the yielded metallic $\mathrm{Mg}$ reacted with hydrogen to form $\mathrm{MgH}_{2}$, where the dissociated oxygen atoms combined with hydrogen to form a vapor of water molecules that were continuously evacuated outside of the system. As a result, the volume fraction of $\mathrm{MgH}_{2}$ was increased against $\mathrm{MgO}$, leading to the enhancement of the hydrogenation/dehydrogenation kinetics (Figure 14a). More importantly, surface cleaning of $\mathrm{MgH}_{2}$ powders enhanced the kinetics of hydrogenation/dehydrogenation processes, as implied by the powder capability of achieving $1400 \mathrm{~h}$ ( 60 days) of charging/discharging processes with the absence of failure, as displayed in Figure 14a. However, this long testing time led to obvious degradation in both the hydrogenation/dehydrogenation kinetics of the last cycle (Figure 14c) when compared with the first cycle (Figure 14b).
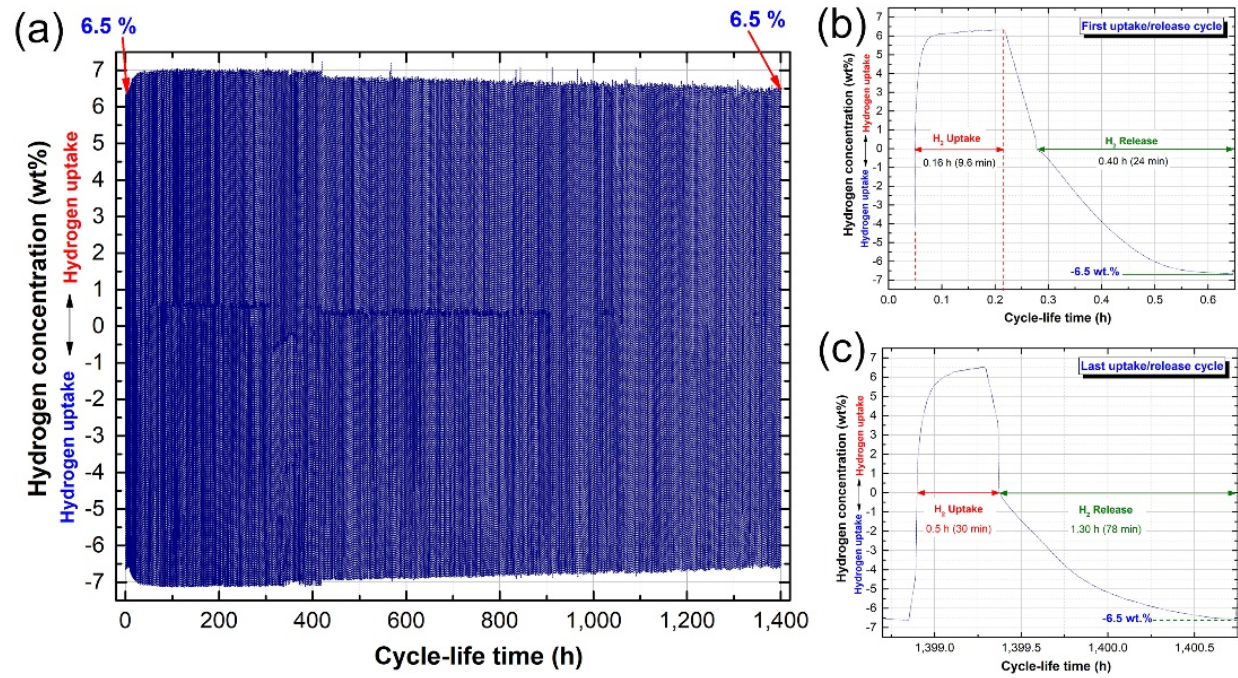

Figure 14. (a) Hydrogenation/dehydrogenation cycle lifetime of $\mathrm{MgH}_{2} / 5 \mathrm{wt} \% \mathrm{ZrC}$ binary system, examined for $1400 \mathrm{~h}$ at $225^{\circ} \mathrm{C}$ under uptake and hydrogen pressures of 10 and 0.4 bar, respectively. The hydrogenation/dehydrogenation cycles after the first and last cycles are presented in $(\mathbf{b}, \mathbf{c})$, respectively.

However, a marginal decrease ( less than 0.5 wt. $\% \mathrm{H}_{2}$ ) in the storage capacity was detected after a compilation of $1400 \mathrm{~h}$, as displayed in Figure 14a. This may be attributed to a moderate grain growth that occurred in $\mathrm{MgH}_{2}$ powders due to the long processing cycle lifetime. It was necessary to examine the morphological characteristics and local structure of powders after such a long cycle lifetime.

The FE-SEM image of the cycled powders is presented in Figure 15. The powders were composed of dark-grey $\mathrm{Mg}$ aggregates with a rough surface, containing numerous numbers of pores with a crater-like morphology, as displayed in Figure 15. The presence of such pores facilitated successful hydrogen absorption/desorption. Besides, the $\mathrm{ZrC}$ nanopowders were embedded into the surface and subsurface of $\mathrm{Mg}$ metal through the pores to act as a grain growth inhibitor, as shown in Figure 15. 


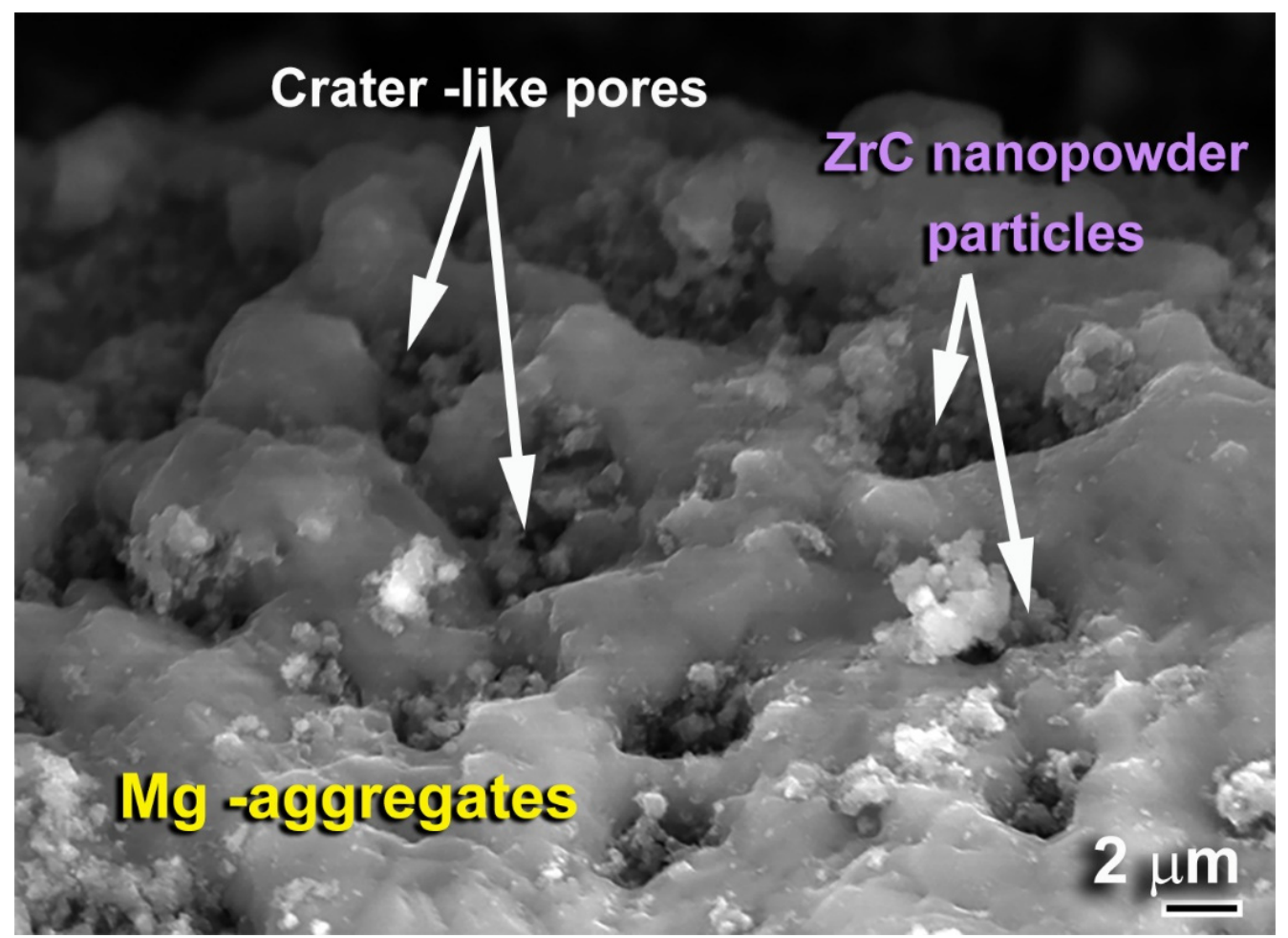

Figure 15. FE-SEM micrograph of $\mathrm{MgH}_{2} / 5 \mathrm{wt} . \% \mathrm{ZrC}$ binary system, obtained after achieving $1400 \mathrm{~h}$ of cycle lifetime at $225^{\circ} \mathrm{C}$ under uptake and hydrogen pressures of 10 and 0.4 bar, respectively (see Figure 14c).

The local structure of the nanocomposite $\mathrm{MgH}_{2} / 5 \mathrm{wt} \% \mathrm{ZrC}$ system obtained after a cycle lifetime for $1400 \mathrm{~h}$ was examined with atomic-resolution FE-TEM. The HRTEM image displayed fringe nanograins related to $\beta-\mathrm{MgH}_{2}$ (zone I in Figure 16a) oriented to the axis zone of (110), as displayed in Figure 16b. Besides, a ZrC nanograin (zone II in Figure 16a) was embedded into the $\mathrm{MgH}_{2}$ matrix, as indicated by the interplanar spacing $(0.236 \mathrm{~nm})$, which corresponds to $\mathrm{ZrC}$ (200), as presented in Figure 16c. It is worth mentioning that we could not detect any reacted phase such as pure hcp- $\mathrm{Zr}$, fcc- $\mathrm{ZrH}_{2}$, and /or $\mathrm{MgZr}$ phases. This may suggest that $\mathrm{ZrC}$ nanopowder is a typical heterogeneous catalyst, where it does not react with $\mathrm{MgH}_{2}$ to form any intermediate phase.

Comparison of the present results indicates the capability of the $\mathrm{MgH}_{2} / \mathrm{ZrC}$ binary system to achieve a long cycle lifetime with excellent performance. For example, $\mathrm{MgH}_{2} / \mathrm{Mn}_{2} \mathrm{Ti}$ [33] and $\mathrm{MgH}_{2} / 10 \mathrm{wt} \%$ big-cube $\mathrm{Zr}_{2} \mathrm{Ni}$ [35] systems showed excellent performances for achieving about $1400 \mathrm{~h}$; however, the process was undertaken at higher temperatures $\left(250{ }^{\circ} \mathrm{C}\right.$ to $\left.275^{\circ} \mathrm{C}\right)$ under a hydrogen pressure of 10 bar. These systems, however, had a lower hydrogen storage capacity of less than $5 \mathrm{wt} \% \mathrm{H}_{2}$ and suffered from slower uptake/release kinetics. The advantages of using $\mathrm{ZrC}$ particles as a hydrogen storage modifier for the $\mathrm{MgH}_{2}$ binary system may be attributed to the abrasion effect of $\mathrm{ZrC}$ nanopowders, which led to a severe reduction in $\mathrm{MgH}_{2}$ powders upon HEBM. Moreover, the $\mathrm{ZrC}$ nanopowders played a critical role as a grain growth inhibitor that prevented $\mathrm{MgH}_{2}$ powders from severely increasing in size, thus overcoming any undesired kinetics degradation during the long cycle lifetime. 


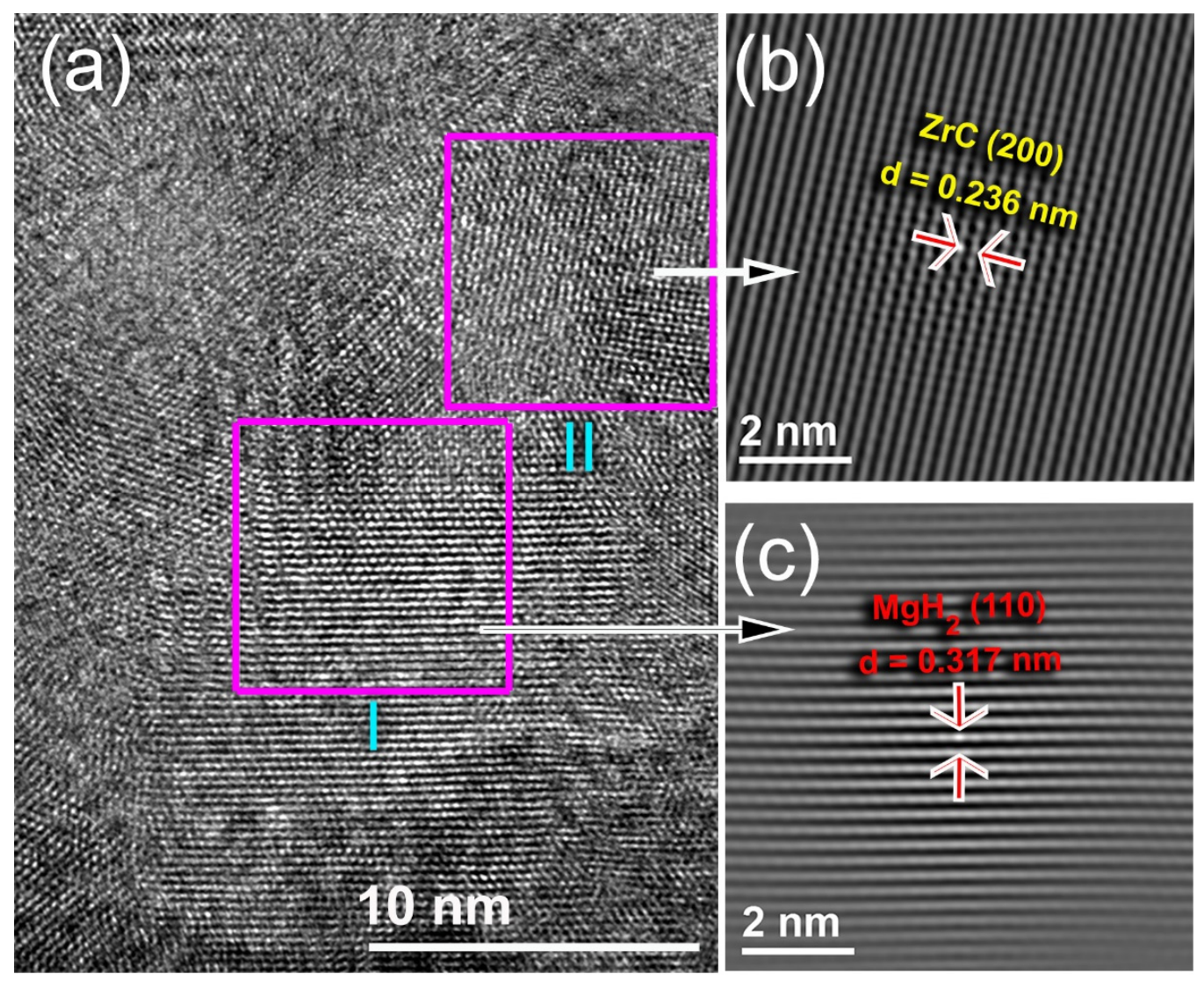

Figure 16. (a) FE-HRTEM image of $\mathrm{MgH}_{2} / 5$ wt. $\% \mathrm{ZrC}$ binary system, obtained after achieving $1400 \mathrm{~h}$ of cycle lifetime at $225^{\circ} \mathrm{C}$ under uptake and hydrogen pressures of 10 and 0.4 bar, respectively. The corresponding filtered atomic resolution images taken for zones I and II are displayed in $(\mathbf{b}, \mathbf{c})$, respectively.

\section{Materials and Methods}

\subsection{Materials Preparations}

3.1.1. Preparations of Nanocrystalline $\mathrm{MgH}_{2}$ Powders

Elemental powders of $\mathrm{Mg}(99.9 \mathrm{wt} \%, 80 \mu \mathrm{m})$ were provided by Alfa Aesar (CAS Number 7439-95-4), Kandel, Germany, and high-purity (99.999 wt.\%) hydrogen gas was used as starting materials. A small amount $(\sim 5 \mathrm{~g})$ of the powder was sealed into a tool steel vial (150 mL), using a GST (gas-temperature-monitoring system) inside a helium (He) gas atmosphere-glove box (UNILAB Pro Glove Box Workstation, mBRAUN, Daimlerstraße 29-31, D-76316 Malsch, Germany). A quantity of 50 tool steel balls (11 $\mathrm{mm}$ in diameter) were used as milling media. The ball-to-powder weight ratio was 42 to 1 . The vial was then pressurized with 50 bar of hydrogen. The reactive ball milling was carried out at room temperature for 25 to $50 \mathrm{~h}$ with a rotation speed of $250 \mathrm{rpm}$, using a planetary-type ball mill (PM400) provided by RETSCH GmbH, Berlin, Germany.

\subsubsection{Preparations of $\mathrm{ZrC}$ Nanopowders}

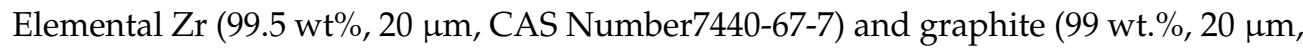
CAS Number7782-42-5) powders, provided by Alfa Aesar, Kandel, Germany, were employed as feedstock materials. The two powder species were balanced and mixed inside the glove box to obtain $5 \mathrm{~g}$ of equiatomic composition. The powders were then sealed in a tool steel vial $(150 \mathrm{~mL}$ ) together with 50 tool steel balls (11 $\mathrm{mm}$ in diameter), using a ball-to-powder weight ratio of 40 to 1 . The system was mounted on the planetary-type ball mill (PM400), where the milling process started at room temperature for $25 \mathrm{~h}$ with a rotation speed of $250 \mathrm{rpm}$. 


\subsubsection{Preparations of Nanocomposite $\mathrm{MgH}_{2} / \mathrm{ZrC}$ Nanopowders}

The as-milled $\mathrm{MgH}_{2}$ powders were doped with the desired mass of as-prepared $\mathrm{ZrC}$ to obtain three nominal compositions of $\mathrm{MgH}_{2} / \mathrm{x}$ wt $\% \mathrm{ZrC}(\mathrm{x} ; 2,5$ and 7$)$ inside the glove box. The three composite systems were individually charged into tool steel vials $(150 \mathrm{~mL})$ and sealed together with 50 tool steel balls $(11 \mathrm{~mm})$, using $45: 1$ as the ball-to-powder weight ratio. The vial was then pressurized with 50 bar of hydrogen. The mechanically induced solid-state mixing was conducted at a milling speed of $250 \mathrm{rpm}$ for $25 \mathrm{~h}$, using a planetary-type ball mill (PM400).

\subsection{Sample Characterizations}

\subsubsection{Crystal Structure and Morphology}

$X$-ray diffraction $(\mathrm{XRD})$ with $\mathrm{CuK} \alpha$ radiation was employed to investigate the average crystal structure of all samples, using the $9 \mathrm{~kW}$ Intelligent $X$-ray diffraction system, provided by SmartLab-Rigaku, Kawasaki, Japan. Then, a 200 kV-field-emission high-resolution transmission electron microscope (FE-HRTEM, JEOL-2100 F), supplied by JEOL, Chiba, Japan, was used to investigate the local structure of the synthesized powders. The morphological properties of the powders were studied by a $15 \mathrm{kV}$-field-emission scanning electron microscope (FE-SEM, JSM-7800 F/EDS, Chiba, Japan). The local composition of the as-prepared samples was investigated via FE-SEM/energy-dispersive $X$-ray spectroscopy (EDS, Oxford Instruments, Andor, 277.3 mi, Belfast, UK).

\subsubsection{Thermal Stability}

The thermal stability of the samples was investigated by the Shimadzu Thermal Analysis System (TA-60 WS, Tokyo, Japan), using a differential scanning calorimeter (DSC) with different heating rates of $5,10,20,30$, and $40{ }^{\circ} \mathrm{C} / \mathrm{min}$. All DSC measurements were conducted under a flow $(75 \mathrm{mi} / \mathrm{min})$ of He.

\subsubsection{Hydrogenation/Dehydrogenation Kinetics}

The absorption/desorption kinetics behavior of the samples were investigated via Sievert's method, using PCTPro-2000, provided by Setaram Instrumentation, 12 Rue de Verdun, 69,300 Caluire-et-Cuire, France. An amount of 250-280 mg of the powders was handled and balanced to obtain the desired mass inside the He-glove box. The powders were then sealed into a vial made of chromium-resistance $\left(\right.$ Swagelok ${ }^{\circledR}$ ) alloy inside the glove box. The vial was then inserted inside a portable standard autoclave $\mathrm{Cu}$-clad holder. Prior to the kinetics measurements, the powders were activated at $350{ }^{\circ} \mathrm{C}$ under 35 bar of hydrogen overnight. Then, six volume calibrations were individually conducted at room temperature and at the desired measurement temperature.

\section{Conclusions}

Reactive ball milling was employed to fabricate nanocrystalline $\mathrm{MgH}_{2}$ powders in a gas-solid reaction fashion performed under high hydrogen pressure ( $\sim 50$ bar) for $25 \mathrm{~h}$ to $50 \mathrm{~h}$. The hydrogenation/dehydrogenation kinetics of the as-prepared $\mathrm{MgH}_{2}$ powder was very slow and required the application of high temperature (above $325^{\circ} \mathrm{C}$ ) to absorb/desorb $6.5 \mathrm{wt} . \% \mathrm{H}_{2}$ within $2500 \mathrm{~s}$ and $7800 \mathrm{~s}$, respectively. Besides, the as-prepared $\mathrm{MgH}_{2}$ system obtained after $50 \mathrm{~h}$ of reactive ball milling possessed a high decomposition temperature of $376^{\circ} \mathrm{C}$ at a heating rate of $20^{\circ} \mathrm{C} / \mathrm{min}$ with an apparent activation energy of $123 \mathrm{~kJ} / \mathrm{mol}$. To improve the hydrogen storage behavior of the as-prepared $\mathrm{MgH}_{2}$ binary system, ultrafine fcc- $\mathrm{ZrC}$ nanopowder was prepared via the carbonization reaction between metallic $\mathrm{Zr}$ and graphite powders, using a room-temperature high-energy ball mill. The as-prepared $\mathrm{ZrC}$ powders obtained after $25 \mathrm{~h}$ of milling possessed good morphological properties of being an ultrafine powder (less than $50 \mathrm{~nm}$ in diameter) with spherical-like nanograins, ranging between 2 and $7 \mathrm{~nm}$ in diameter. In the present work, $\mathrm{MgH}_{2}$ powders were doped with three individual concentrations of $\operatorname{ZrC~}(2,5$ and $7 \mathrm{wt} . \%)$ and high-energy ball-milled for $25 \mathrm{~h}$. The results showed that $\mathrm{ZrC}$ powders acted as micro-milling media to reduce the $\mathrm{MgH}_{2}$ particle size to a minimal value that could not be obtained without $\mathrm{ZrC}$. 
After $25 \mathrm{~h}$ of milling, the hard $\mathrm{ZrC}$ nanopowders were embedded into the $\mathrm{MgH}_{2}$ matrix to form nanocomposite $\mathrm{MgH}_{2} / \mathrm{ZrC}$ powders that had an homogeneous composition and fair distribution of $\mathrm{ZrC}$ particles beyond the nano-level. The $\mathrm{ZrC}$ agent led to the minimization of the decomposition temperature $\left(287^{\circ} \mathrm{C}\right)$ of $\mathrm{MgH}_{2}$ and lowering in the apparent activation energy of desorption for $\mathrm{MgH}_{2}$ to $69 \mathrm{~kJ} / \mathrm{mol}$. The hydrogenation/dehydrogenation kinetics of the nanocomposite $\mathrm{MgH}_{2} / \mathrm{ZrC}$ system revealed significant improvement, as indicated by the low temperature and short time required to achieve successful uptake and release processes. This system possessed a high capability of tackling a long continuous cycle lifetime $(1400 \mathrm{~h})$ at low temperature $\left(225^{\circ} \mathrm{C}\right)$ without showing serious degradation in its storage capacity.

Author Contributions: M.S.E.-E. designed the experimental work, shared in the samples preparations, made the SEM and TEM characterizations, and wrote the manuscript. N.A. shared in sample preparations and XRD analysis, and reviewed the manuscript. M.B. and F.A.-A., who equally contributed to this work, made the kinetics analysis and DSC measurements. All authors discussed the results and commented on the manuscript and conclusions of this work. All authors have read and agreed to the published version of the manuscript.

Funding: This work has been partially funded by the Kuwait Foundation for the Advancement of Sciences (KFAS) related to the Project EA078 C under a contract number: PR1814 SP12.

Institutional Review Board Statement: Not applicable.

Informed Consent Statement: Not applicable.

Data Availability Statement: Not available.

Acknowledgments: The financial support received by the Kuwait Government through the Kuwait Institute for Scientific Research for purchasing the equipment used in the present work, using the budget dedicated for the project led by the first author (P-KISR-06-04) of the Establishing Nanotechnology Center in KISR, is highly appreciated. The permission for publications of this work was allowed from Kuwait Institute for Scientific Research.

Conflicts of Interest: The authors declare that they have no conflict of interest.

Sample Availability: Samples of the compounds are not available from the authors.

\section{References}

1. Vohra, K.; Vodonos, A.; Schwartz, J.; Marais, E.; Sulprizio, M.; Mickley, L. Global mortality from outdoor fine particle pollution generated by fossil fuel combustion: Results from GEOS-Chem. Environ. Res. 2021, 195, 110754. [CrossRef]

2. Jackson, R.B.; Quéré, C.L.; Andrew, R.M.; Canadell, J.G.; Peters, G.P.; Roy, J.; Wu, L. Warning signs for stabilizing global CO 2 emissions. Environ. Res. Lett. 2017, 12, 110202-110206. [CrossRef]

3. El-Eskandarany, M.S. Recent developments in the fabrication, characterization and implementation of $\mathrm{MgH}_{2}$-based solidhydrogen materials in the Kuwait Institute for Scientific Research. RSC Adv. 2019, 9, 9907. [CrossRef]

4. Rango, P.; Wen, J.; Skryabina, N.; Laversenne, L.; Fruchart, D.; Borges, M. Hydrogen Storage Properties of Mg-Ni Alloys Processed by Fast Forging. Energies 2020, 13, 3509. [CrossRef]

5. El-Eskandarany, M.S.; Al-Salem, S.; Ali, N.; Banyan, M.; Al-Ajimi, F.; Al-Duweesh, A. From gangue to the fuel-cells application. Sci. Rep. 2020, 10, 20022. [CrossRef] [PubMed]

6. $\quad$ El-Eskandarany, M.S. Mechanical Alloying: Energy, Surface Protective Coating and Medical Applications, 3rd ed.; Elsevier, Oxford University Press: New York, NY, USA, 2020.

7. Sinigaglia, T.; Lewiski, F.; Martins, M.E.S.; Siluk, J.C.M. Production, storage, fuel stations of hydrogen and its utilization in automotive applications-a review. Int. J. Hydrogen Energy 2017, 42, 24597-24611. [CrossRef]

8. El-Eskandarany, M.S.; Al-Nasrallah, E.; Banyan, M.; Al-Ajmi, F. Bulk nanocomposite $\mathrm{MgH}_{2} / 10 \mathrm{wt} . \%\left(8 \mathrm{Nb} 2 \mathrm{O}_{5} / 2 \mathrm{Ni}\right)$ solidhydrogen storage system for fuel cell applications. Int. J. Hydrogen Energy 2018, 27, 23382-23396. [CrossRef]

9. Walker, G. Hydrogen containment materials, In Solid-State Hydrogen Storage: Materials and Chemistry, 1st ed.; Woodhead Publishing Limited, Elsevier: New York, NY, USA, 2008.

10. Jeon, S.; Roh, M.; Heshmati, A.; Kim, S. An assessment of corporate average fuel economy standards for passenger cars in South Korea. Energies 2020, 13, 4533. [CrossRef]

11. Sakintuna, B.; Lamari-Darkrim, F.; Hirscher, M. Metal hydride materials for solid hydrogen storage: A review. Int. J. Hydrogen Energy 2007, 32, 1121-1140. [CrossRef] 
12. Shao, H. Heat modeling and material development of mg-based nanomaterials combined with solid oxide fuel cell for stationary energy storage. Energies 2017, 10, 1767. [CrossRef]

13. Peska, M.; Crujko, T.; Polanski, M. Hydrogenation ability of Mg-Li alloys. Energies 2020, 13, 2080. [CrossRef]

14. Shukla, V.; Bhatnagar, A.; Verma, S.; Pandey, A.; Vishwakarma, A.; Srivastava, P.; Yadav, T.; Srivastava, O. Simultaneous improvement of kinetics and thermodynamics based on $\mathrm{SrF}_{2}$ and $\mathrm{SrF}_{2} @ \mathrm{Gr}$ additives on hydrogen sorption in $\mathrm{MgH}_{2}$. Mater. Adv 2021, 2, 4277-4290. [CrossRef]

15. El-Eskandarany, M.S.; Saeed, M.; Al-Nasrallah, E.; Al-Ajmi, F.; Banyan, M. Effect of $\mathrm{LaNi}_{3}$ amorphous alloy nanopowders on the performance and hydrogen storage properties of $\mathrm{MgH}_{2}$. Energies 2019, 12, 1005. [CrossRef]

16. Zhang, X.; Liu, Y.; Zhang, X.; Hu, J.; Gao, M.; Pan, H. Empowering hydrogen storage performance of $\mathrm{MgH}_{2}$ by nanoengineering and nanocatalysis. Mater. Today Nano 2020, 9, 100064. [CrossRef]

17. El-Eskandarany, M.S.; Shaban, E.; Al-Matrouk, H.; Behbehani, M.; Alkandary, A.; Aldakheel, F.; Ali, N.; Ahmed, S.A. Structure, morphology and hydrogen storage kinetics of nanocomposite $\mathrm{MgH}_{2} / 10 \mathrm{wt} \% \mathrm{ZrNi}_{5}$ powders. Mater. Today Energy 2017, 3, 60-71. [CrossRef]

18. El-Eskandarany, M.S. Metallic glassy $\mathrm{Zr}_{70} \mathrm{Ni}_{20} \mathrm{Pd}_{10}$ powders for improving the hydrogenation/dehydrogenation behavior of $\mathrm{MgH}_{2}$. Sci. Rep. 2016, 6, 26936. [CrossRef] [PubMed]

19. Luo, Q.; Li, J.; Li, B.; Liu, B.; Shao, H.; Li, Q. Kinetics in Mg-based hydrogen storage materials: Enhancement and mechanism. J. Magnes. Alloy 2019, 7, 58-71. [CrossRef]

20. Wang, Y.; Wang, Y.J. Recent advances in additive-enhanced magnesium hydride for hydrogen storage. Prog. Nat. Sci. 2017, 27, 41-49. [CrossRef]

21. El-Eskandarany, M.S.; Shaban, E.; Al-Halaili, B. Nanocrystalline $\beta-\gamma-\beta$ cyclic phase transformation in reacted ball milled $\mathrm{MgH}_{2}$ powders. Int. J. Hydrogen Energy 2014, 39, 12727-12740. [CrossRef]

22. Amira, S.; Huot, J. Effect of cold rolling on hydrogen sorption properties of die-cast and as-cast magnesium alloys. J. Alloys Compd. 2012, 520, 287-294. [CrossRef]

23. Huot, J.; Tousignant, M. Effect of cold rolling on metal hydrides. Mater. Trans. 2019, 60, 1571-1576. [CrossRef]

24. Jorge, A.M., Jr.; de Lima, G.F.; Triques, M.R.M.; Botta, W.J.; Kiminami, C.S.; Nogueira, R.P.; Yavari, A.R.; Langdon, T.G. Correlation between hydrogen storage properties and textures induced in magnesium through ecap and cold rolling. Int. J. Hydrogen Energy 2014, 39, 3810-3821. [CrossRef]

25. Valiev, R.Z.; Islamgaliev, R.K.; Alexandrov, I.V. Bulk nanostructured materials from severe plastic deformation. Prog. Mater. Sci. 2000, 45, 103-189. [CrossRef]

26. Vajeeston, P.; Ravindran, P.; Kjekshus, A.; Fjellvåg, H. Pressure-induced structural transitions in MgH 2 . Phys. Rev. Lett. 2002, 89, 175506. [CrossRef]

27. Xie, L.S.; Li, J.S.; Zhang, T.B.; Kou, H.C. Role of milling time and ni content on dehydrogenation behavior of MgH2/Ni composite. T. Nonferr. Metal SOC 2017, 27, 569-577. [CrossRef]

28. Liang, G.; Huot, J.; Boily, S.; Van Neste, A.; Schulz, R. Catalytic effect of transition metals on hydrogen sorption in nanocrystalline ball milled $\mathrm{MgH}_{2}-\mathrm{TM}(\mathrm{TM}=\mathrm{Ti}, \mathrm{V}, \mathrm{Mn}, \mathrm{Fe}$ and Ni) systems. J. Alloys Compd. 1999, 292, 247-252. [CrossRef]

29. House, S.D.; Vajo, J.J.; Ren, C.; Rockett, A.A.; Robertson, I.M. Effect of ball-milling duration and dehydrogenation on the morphology, microstructure and catalyst dispersion in $\mathrm{Ni}$-catalyzed $\mathrm{MgH}_{2}$ hydrogen storage materials. Acta Mater. 2015, 86, 55-68. [CrossRef]

30. Xu, C.C.; Xiao, X.Z.; Jie, S.; Liu, L.X.; Teng, Q.; Chen, L.X. Effects of Ti-based additives on $\mathrm{Mg}_{2} \mathrm{FeH}_{6}$ dehydrogenation properties. T. Nonferr. Metal SOC 2016, 26, 791-798. [CrossRef]

31. Yu, X.; Yang, Z.; Liu, H.-K.; Grant, D.; Walker, G.S. The effect of a Ti-V-based bcc alloy as a catalyst on the hydrogen storage properties of $\mathrm{MgH}_{2}$. Int. J. Hydrogen Energy 2010, 35, 6338-6344. [CrossRef]

32. Zhou, C.; Fang, Z.Z.; Ren, C.; Li, J.; Lu, J. Effect of Ti intermetallic catalysts on hydrogen storage properties of magnesium hydride. J. Phys. Chem. C 2013, 117, 12973-12980. [CrossRef]

33. El-Eskandarany, M.S.; Al-Matrouk, H.; Shaban, E.; Al-Duweesh, A. Effect of mechanically-induced solid-state doping time on the morphology and hydrogenation cyclability of $\mathrm{MgH}_{2} / 7 \mathrm{Mn}_{3.6} \mathrm{Ti}_{2.4}$ nanocomposite powders. Int. J. Hydrogen Energy 2015, 40, 10139-10149. [CrossRef]

34. Ren, C.; Fang, Z.Z.; Zhou, C.; Lu, J.; Ren, Y.; Zhang, X. Hydrogen storage properties of magnesium hydride with V-based additives. J. Phys. Chem. C 2014, 118, 21778-21784. [CrossRef]

35. El-Eskandarany, M.S.; Al-Matrouk, H.; Shaban, E.; Al-Duweesh, A. Superior catalytic effect of nanocrystalline big-cube $\mathrm{Zr}_{2} \mathrm{Ni}$ metastable phase for improving the hydrogen sorption/desorption kinetics and cyclability of $\mathrm{MgH}_{2}$ powders. Energy 2015, 91, 274-282. [CrossRef]

36. Polanski, M.; Bystrzycki, J.; Varin, R.A.; Plocinski, T.; Pisarek, M. The effect of chromium (iii) oxide $\left(\mathrm{Cr}_{2} \mathrm{O}_{3}\right)$ nanopowder on the microstructure and cyclic hydrogen storage behavior of magnesium hydride $\left(\mathrm{MgH}_{2}\right)$. J. Alloys Compd. 2011, 509, $2386-2391$. [CrossRef]

37. Ma, Z.; Liu, J.; Zhu, Y.; Zhao, Y.; Lin, H.; Zhang, Y.; Li, H.; Zhang, J.; Liu, Y.; Gao, W. Crystal-facet-dependent catalysis of anatase $\mathrm{TiO}_{2}$ on hydrogen storage of $\mathrm{MgH}_{2}$. J. Alloys Compd. 2020, 822, 153553. [CrossRef]

38. Gupta, R.; Agresti, F.; Russo, S.L.; Maddalena, A.; Palade, P.; Principi, G. Structure and hydrogen storage properties of $\mathrm{MgH}_{2}$ catalysed with $\mathrm{La}_{2} \mathrm{O}_{3}$. J. Alloys Compd. 2008, 450, 310-313. [CrossRef] 
39. El-Eskandarany, M.S.; Alkandary, A.; Aldakheel, F.; Al-Saidi, M.; Al-Ajmi, F.; Banyan, M. Performance and fuel cell applications of reacted ball-milled $\mathrm{MgH}_{2} / 5.3 \mathrm{wt}$.\% $\mathrm{TiH}_{2}$ nanocomposite powders. RSC Adv. 2018, 8, 38175-38185. [CrossRef]

40. Song, J.Z.; Zhao, Z.Y.; Zhao, X.; Fu, R.D.; Han, S.M. Hydrogen storage properties of $\mathrm{MgH}_{2} \mathrm{Co}_{\text {-catalyzed by LaH }}$ and $\mathrm{NbH}$ Int. J. Miner. Metall. Mater. 2017, 24, 1183-1191. [CrossRef]

41. Ranjbar, A.; Guo, Z.; Yu, X.; Wexler, D.; Calka, A.; Kim, C.; Liu, H.-K. Hydrogen storage properties of $\mathrm{MgH}_{2}-\mathrm{SiC}$ composites. Mater. Chem. Phys. 2009, 114, 168-172. [CrossRef]

42. El-Eskandarany, M.S.; Shaban, E.; Alsairafi, A.A. Synergistic dosing effect of TiC/FeCr nanocatalysts on the hydrogenation/dehydrogenation kinetics of nanocrystalline $\mathrm{MgH}_{2}$ powders. Energy 2016, 104, 158-170. [CrossRef]

43. Pandyan, R.K.; Seenithurai, S.; Mahendran, M. Hydrogen storage in $\mathrm{MgH}_{2}$ coated single walled carbon nanotubes. Int. J. Hydrogen Energy 2011, 36, 3007-3015. [CrossRef]

44. Singh, M.K.; Bhatnagar, A.; Pandey, S.K.; Mishra, P.; Srivastava, O. Experimental and first principle studies on hydrogen desorption behavior of graphene nanofiber catalyzed $\mathrm{MgH}_{2}$. Int. J. Hydrogen Energy 2017, 42, 960-968. [CrossRef]

45. El-Eskandarany, M.S.; Ali, N.; Banyan, M.; Al-Ajmi, F. Cold gas-dynamic spray for catalyzation of plastically deformed Mg-strips with Ni powder. Nanomaterials 2021, 11, 1169. [CrossRef] [PubMed] 